\title{
Spectrum of Congenital Anomalies among Children Attending the Pediatric Departments of Dhaka Medical College Hospital
}

\author{
Dr. Chowdhury Fazle Mubarak Bari
}

\begin{abstract}
Introduction: Congenital anomalies (CA), which refer to morphologic defects that occur during the process of human development in the womb usually clinically apparent at birth, are an important cause of mortality in newborns and a major cause of mortality and morbidity in children globally as well as Bangladesh, affecting not only the lives of the children but also their families, health care providers and societies. However, sufficient and up-to-date data regarding the variations of CA among children in Bangladesh especially of those who have survived after birth are largely lacking.

Objective: To determine the spectrum of congenital anomalies among children attending the Departments of Pediatric Medicine and Surgery in Dhaka Medical College Hospital.

Methodology: A descriptive study was conducted from April to October 2013 to explore the variations and patterns of distribution of congenital anomalies among children attending the Departments of Pediatric Medicine and Surgery in Dhaka Medical College Hospital. Detailed information was collected from mothers (respondents) and hospital files of 267 children with CAs on a predesigned pro-forma and analyzed using SPSS for frequencies and distributions.

Results: Out of 267 children with CAs, digestive system accounted for majority of the cases 27\% ( $n=72)$ followed by nervous system, $15.7 \%(n=42)$; genitourinary system, 15.7\% (n=42); and others. Overall, congenital hydrocephalus $8.6 \%(n=23)$ was the most common followed by hypospadias $7.9 \%(n=21)$ and Hirschsprung's disease $7.5 \%(n=20) .71 .9 \%$ (192) of the patients were treated and discharged with correction of anomaly while only $3 \%(n=8)$ of the patients died during hospital stay. Early neonates (1-7days) were the most common age group of the children (33.3\%); $52.8 \%$ of the patients were males; $91.8 \%$ of the respondents were Muslims; majority (44.9\%) of the mothers were between 21-25 years of age at conception; 6\% of respondents had family history of birth defects; and 3.4\% of the respondents had consanguineous marriages. Majority of the mothers (40.4\%) and fathers (32.2\%) received education up to or below $6^{\text {th }}$ grade; majority (65\%) of respondents had monthly income of less than 10,000 Tk. $15 \%$ of the mothers had regular antenatal checkups; $30.7 \%$ took iron, folic acid and vitamin B12 supplementation during pregnancy; none were found to be active smokers; and scattered cases of maternal diabetes, hypertension and epilepsy were encountered.

Conclusions: A wide variety of congenital anomalies with varying patterns of distribution was recorded. Health care facilities in Dhaka Medical College Hospital were found to be relatively adequate. Socio-economic conditions and educational levels of parents having children with congenital anomalies were found to be under par. In addition, the percentages of patients receiving regular antenatal checkups and vitamin supplementations were found to be alarmingly low. The problem of CAs can be tackled through measures of prevention and treatment which include early recognition, micronutrient supplementation, vaccination, antenatal care, affordable surgical intervention or reconstruction and heightened awareness.
\end{abstract}

Introduction

\section{Introduction}

Human reproduction involves a complex and delicate set of processes which are vulnerable to adverse outcomes if exposed to adverse factors related to host and environment. This may lead to morphologic defects which are collectively called congenital anomalies. Congenital anomalies or CAs are also known as birth defects, congenital disorders or congenital malformations. By definition, congenital anomalies may be regarded as structural or functional anomalies, including metabolic disorders, which are present at the time of birth. ${ }^{1}$ Congenital anomalies are present at birth but some conditions such as cardiac defects and renal anomalies, may not become clinically apparent until later in life.

Since the ancient times, congenital anomalies or birth defects have been a mystery and topic of frequent discussions. Concepts of the causation have evolved over centuries from the ancient beliefs of negative or supernatural forces resulting in birth defects to the modern genetic and molecular theories. Despite huge 
advancements in science, the exact causes of malformations remain unknown in at least half of the cases. However, it is believed that congenital anomalies result from intrinsic abnormalities (malformations) as well as extrinsic disturbances.

The common causes of congenital anomalies can be grouped into genetic, environmental and multifactorial. ${ }^{2}$ Genetic causes include chromosomal aberrations (10-15\%) and Mendelian inheritance $(2-10 \%){ }^{2}$ Down syndrome, Turners syndrome and Klinefelter's syndrome are examples of chromosomal aberrations. Single gene mutations are characterized by Mendelian inheritance. ${ }^{3,4}$ Environmental causes can be divided into Maternal/Placental infections (2-3\%), which include rubella, syphilis, toxoplasmosis, cytomegalovirus and human immune deficiency virus HIV; Maternal disease states (6-8\%) which include diabetes, phenylketonuria and endocrinopathies; Drugs and chemicals (1\%) which include alcohol, folic acid antagonists, androgens, phenytoin, thalidomide, warfarin, 13-cis-retionic acid and others; and Irradiations. ${ }^{2}$ These environmental factors to which the mother is exposed to during pregnancy may cause fetal malformations. ${ }^{3,4}$ Multifactorial causes account for $20-25 \%$ of cases. ${ }^{2}$ Multifactorial inheritance refers to the interplay between environmental factors and two or more genes of small effect. This is the most common genetic cause of congenital malformations. They include common malformations like cleft palate, cleft lip and neural tube defects. An important way of preventing congenital anomalies is by intervening with these environmental influences, for instance preventing maternal infections or drug intake during pregnancy can avert the occurrences of many types of anomalies. Another example can be seen by the mere intake of folic acid during pregnancy which can dramatically reduce the incidence of neural tube defects. 3

$40-60 \%$ of the causes of congenital anomalies are unknown. ${ }^{2}$ In addition to the above mentioned factors, certain indirect determinants or intervening factors of congenital anomalies include socioeconomic and demographic factors. Studies have shown that majority $\left(94 \%^{1}\right)$ of all the congenital malformations occur in middle and low income countries where mothers are exposed to factors of low socioeconomic statuses such as macro and micro-nutrient deficiencies, infections and other factors. Advanced maternal age also increases the chances of certain chromosomal abnormalities.

Human development begins in the intrauterine life as soon as fertilization occurs. Any error occurring during the developmental process results in malformations. In the early embryonic life, an injurious agent may damage cells to cause either abortion or complete recovery. Between the embryonic and fetal period, an assault usually results in teratogens. ${ }^{4,5}$ Fetal period is characterized by organogenesis, and errors during this phase results in growth retardation or injury to already-formed organs. ${ }^{4,5}$

The most frequently occurring fatal congenital anomalies are congenital heart diseases, Neural tube defects and Down syndrome. Approximate frequencies of different types of malformations per 1000 total births in the US are as follows: Clubfoot without central nervous system anomalies had the highest frequency of 25.7 per 1000 total births, followed by patent ductus areteriosus (16.9), ventricular septal defect (10.9), cleft lip with or without cleft palate (9.1), spina bifida without anencephalous (5.5), congenital hydrocephalus without anencephalus (4.8), anencephalus(3.9), reduction deformity of the musculoskeletal system (3.5) and rectal and intestinal atresia (3.4). ${ }^{5}$

The WHO classifies congenital anomalies in the ICD 10 (International Statistical Classification of Diseases and Related Health Problems 10th Revision) Chapter XVII: Congenital malformations, deformations and chromosomal abnormalities. Broadly, congenital anomalies can be clustered according to the system or site affected into Nervous System; Eye, Ear, Face and Neck; Cardiovascular System; Respiratory System; Cleft Lip and Cleft Palate; Digestive System; Genitourinary System; Musculoskeletal System; Chromosomal Abnormalities; and Other Congenital Abnormalities.

About $20 \%^{3}$ of fertilized ova are blighted from the outset due to their nature of anomaly. Less severe ones persist for longer periods of intrauterine life usually ending in spontaneous abortions while a few terminates as still births. Only a few least severe ones permits live births and continue as birth defects or congenital anomalies. ${ }^{4}$ Birth defects that persist after birth are the most common cause of mortality in the first year of life and contribute significantly to the mortality and morbidity of children worldwide having a serious effect on the health, development and functional ability of children.

\section{Justification of the Study}

Congenital anomalies are an important cause of still births and childhood deaths in Bangladesh and contribute to chronic illnesses and disability among children. The burdens of congenital anomalies are felt at a greater magnitude due to the increased presence of risk factors associated with birth defects compared to other countries. In addition, the problem of birth defects is overshadowed by other causes of child mortality and morbidity such as low birth weight, asphyxia, maternal and childhood infections, under-nutrition and other factors for which studies and actions regarding congenital anomalies are largely lacking.

WHO estimates that some 260,000 deaths worldwide (about $7 \%$ of all neonatal deaths) were caused by congenital anomalies in $2004 .{ }^{6}$ CAs are responsible for $17.8 \%$ of infant deaths in the US. ${ }^{7}$ Birth defects affect 
approximately 1 in 33 infants and result in approximately 3.2 million birth defect-related disabilities annually. ${ }^{1}$ Almost around 270,000 newborns die during the first 28 days of life annually from congenital malformations. ${ }^{1}$ In addition congenital anomalies have long term implications affecting the children, their families, health care providers and societies. The magnitude of congenital anomalies is substantial worldwide with a prevalence rate of 23.9 per 1000 live births in Europe, ${ }^{8}$ and is more than 30 to 35 per 1000 live births in the Indian subcontinent as shown by various studies discussed in the literature review section.

In Bangladesh, due to the low socio-economic status of most households, adverse environmental conditions, widespread existence of maternal infections and lack of awareness about birth defects, congenital anomalies have a higher rate of occurrence compared to developed countries. Many of the congenital anomalies can be prevented and treated. Important aspects of prevention and treatment include early recognition, micronutrient supplementation, vaccination, antenatal care and surgical intervention or reconstruction. For example simple preventive measures like the intake of folic acid during pregnancy can drastically reduce the incidence of neural tube defects. And modern affordable surgical reconstructions can repair many of the anomalies. However, despite having the expertise and facilities to tackle the problem to some extent, the burden of congenital anomalies among children in Bangladesh poses a significant health problem largely due to insufficient studies and data especially on the variations or spectrum of the anomalies, inadequate prevention and intervention strategies and lack of awareness among people. Therefore this research, exploring the various spectrums and patterns of distribution of congenital anomalies, gives valuable epidemiologic information based on which further analytic studies can be undertaken and appropriate prevention and intervention strategies can be designed.

\section{Literature Review}

Congenital anomalies or birth defects have been topic of frequent discussion and research throughout history from the early studies during the ancient times to the modern epidemiologic and scientific researches. Teratology, the study of abnormalities of physiological development, stems from Greek tera- tépas teras meaning 'monster' or 'marvel', and $\lambda$ ó ${ }^{\prime} \cos \log o s$, meaning 'the word or study of ${ }^{10}$. The 'study of monsters' dates back from the ancient civilizations and at one time it was believed that presence of birth defects was a divine punishment for wickedness, a belief that occasionally jeopardized the mother's life.

Over the years, numerous studies have been carried out to determine the prevalence, patterns, possible causations, and other factors of congenital malformations. However despite massive advancements and refinements in the study of congenital anomalies, the magnitude of the problem still to this day causes significant health impacts. Some of the important studies that I have gone through are summarized below:

A cross sectional study was carried out in the department of Obstetrics and Gynecology, Bangabandhu Sheikh Mujib Medical University (BSMMU) Hospital in Dhaka to assess the prevalence of congenital anomalies during the period January 2007 to December 2007. In this study, all women giving birth to babies with congenital anomalies were included, with the types of congenital anomaly recorded. Out of 1630 births, 60 (3.68\%) had congenital malformations. Neural tube defect was found to be the commonest (33.33\%) type of anomaly. ${ }^{11}$

Another study on congenital anomalies and related risk factors was under taken at Bangabandhu Sheikh Mujib Medical University in 2004. Congenital malformations were studied prospectively covering 11680 consecutive deliveries. The incidence of malformations was $2.3 \%$. Musculoskeletal system was the most commonly involved. The incidence was higher in still born, premature, low birth weight babies and those with positive familial history. It was also higher in babies born to mothers who were more than 35 years of age and gravida four and above. Also associated with high incidences of congenital anomalies were consanguinity of marriage, drugs and hormone ingestion during pregnancy, antenatal complications like hydramnios, pre eclamtic toxemia and gestational diabetes. ${ }^{12}$

A hospital based prospective study on the pattern of distribution of congenital anomalies in still born was carried out in Ghandi Medical College, Hyderabad, India from July 2007 to December 2009 where all still borns were examined in autopsy and their anomalies were recorded. During this period, out of a total number of births of 17953, 1100 were still born. 102 still borns were studied and congenital anomalies were detected in 28 $(27 \%)$ of them. The most common anomalies were that of central nervous system $(44 \%)$, with anencepahaly being the most common one (50\%). Digestive system anomalies accounted to about $29.5 \%$ and ompalocle was the most common one. Astomia, agnathia, aglossia, atresia along with omphalomesentric cyst were present singly. Urinary system accounted for about $22 \%$, horseshoe shaped kidney being the most common. Other observed anomalies were polycystic kidney disease, distended bladder, congenital posterior urethral valve, congenital bladder obstruction, mega uereter and hydronephrosis. Circulatory system was least with $4.5 \%$ with only one case of dextrocardia. Maternal age ranged from 19 to 28 years with a mean of 23.5 years. Incidence was more in male fetuses in comparison to females with a ratio of $1.7: 1 .^{13}$ 
The pattern of congenital anomalies in newborns was investigated in a hospital based prospective study in Jammu, India during a year period. The numbers of anomalies were greater in males with a sex ratio of 1.6:1.4. The patterns of anomalies were as follows: musculoskeletal (30.6\%), CNS (20.5\%), GIT (18.5\%), skin (7.6\%), genitourinary $(4.7 \%)$, CVS (4\%). Telipes was the most common musculoskeletal anomaly. Congenital anomalies were more common in Muslims (1.77\%) compared to Hindus (1.4)\%, in caesarian born babies $(1.96 \%)$ as compared to vaginally delivered $(1.48 \%)$ and in still born babies $(4.46 \%)$ compared to live borns $(1.39 \%)^{14}$

A rural medical college hospital based data was used to assess the incidence of congenital anomalies and the associated risk factors in the Department of Pediatrics at Mahata Gandhi Institute of Medical Sciences, Sevargram, Wardha. The study included all intramural deliveries between $1^{\text {st }}$ January of 2005 and $31^{\text {st }}$ July of 2007, comprising of 9386 babies and their 9324 mothers. After systemic examinations of the babies for the presence of congenital anomalies, the data were recorded and analyzed to see the distribution and risk factors. Out of the total 92866 babies, 9194 were live births and 192 were still births. The total number of babies with congenital malformations was 179 (1.91\%). Out of the 9262 singleton births, 177 (1.05\%) were malformed, whereas 2 of the 62 pairs of twins had birth defects. Nine of the 179 malformed babies (5.02\%) were still born. Prematurity, increased maternal age, increasing birth order and low birth weight were found to have a higher risk of congenital anomalies. Cardiovascular malformations were most common in live births, followed by musculoskeletal and genitourinary anomalies. ${ }^{15}$

A prospective study to detect the frequency and distribution of congenital surgical malformations in a rural hospital setting in Maharashtra was carried out in 2002. Out of 3000 consecutive births for over a 9 month period, the frequency of congenital malformations was 21.1 per 1000 births. The commonest systems affected were the gastro-intestinal tract and genitourinary tract (20.4\%) followed by the central nervous system (17.3\%). There was higher incidences of congenital malformations with increasing maternal age (>35 years), higher gravida $(>\mathrm{G} 4)$, parental consanguineous marriages, previous history of abortions and maternal hypertension. ${ }^{16}$

In a study, the prevalence of major congenital anomalies in Europe was recorded to be 23.9 per 1,000 births for 2003-2007. $80 \%$ were live births. $2.5 \%$ of live births with congenital anomaly died in the first week of life. $2.0 \%$ were stillbirths or fetal deaths from 20 weeks gestation. $17.6 \%$ of all cases were terminations of pregnancy following prenatal diagnosis (TOPFA). The prevalence of chromosomal anomalies was 3.6 per 1,000 births, contributing $28 \%$ of stillbirths/fetal deaths from 20 weeks gestation with congenital anomaly, and $48 \%$ of all TOPFA. Congenital heart defects (CHD) were the most common non-chromosomal subgroup, at 6.5 per 1,000 births, followed by limb defects $(3.8$ per 1,000), anomalies of urinary system $(3.1$ per 1,000$)$ and nervous system defects $(2.3$ per 1,000$)$. In 2004 , perinatal mortality associated with congenital anomaly was 0.93 per 1,000 births, and TOPFA 4.4 per 1,000 births, with considerable country variation. ${ }^{17}$

A study was carried out in Ecuador in order to determine the prevalence of congenital malformations among children. The prevalence of admissions by birth defects was recorded using official database of hospitals of Ecuador in order to set the basis for a new National Register of Birth Defects. A total of 51, 375 discharges by congenital malformations were registered in a seven year period. 16, 679 of the children with birth defects were less than one year of age. Birth prevalence rate was $72.33 / 10000$ births. $77 \%$ of the congenital defects comprised of the 50 most common birth defects observed in this age group. The most common was cleft lip in children less than one year and second common in children 1 to 5 years. Unilateral cleft lip showed a birth prevalence rate of 4.57/10,000 births. Cardiac defects had a birth prevalence rate of 4.2, hydrocephalus 3.77, and Down's Syndrome 3.70. Undescended testes were the most prevalent birth defect in children between one to 5 years. $55.9 \%$ of the subjects were male, and $42.1 \%$ were female. BPR in males was 40.45 and in females $30.40 .^{18}$

A study was carried out in the United States, to determine the prevalence of congenital anomalies in infants with in utero exposure to antiretrovirals. Data regarding 1112 infants enrolled in the International Pediatric Adolescent AIDS Clinical Trials Group born between 2002 and 2007 were taken for the study. Associations between congenital anomalies and exposure to antiretrovirals were evaluated by logistic regression analysis. 61 of the 1112 infants had congenital anomalies with a prevalence of 5.49/100 live births. Among the 80 anomalies, the organ systems involved were cardiovascular (33), musculoskeletal (15), renal (9), genitourinary (6), craniofacial (4), and central nervous system (2). First trimester exposure to antiretrovirals was associated with significantly increased risk of congenital anomalies with an odds ratio of 2.84. The known teratogen was efavirenz as no significant associations were observed between exposures to other antiretrovirals started at any time during pregnancy. ${ }^{19}$

To examine the associations between paternal age and congenital anomalies, National Birth Defect Prevention Study was carried out in different states of United States from 1997 to 2004 using logistic regression models. Elevated odds ratios for each year increase in paternal age were found for cleft palate (odds ratio (OR) $=1.02,95 \%$ confidence interval $(\mathrm{CI}): 1.00,1.04)$, diaphragmatic hernia $(\mathrm{OR}=1.04,95 \% \mathrm{CI}: 1.02,1.06)$, right ventricular outflow tract obstruction $(\mathrm{OR}=1.03,95 \% \mathrm{CI}: 1.01,1.04)$, and pulmonary valve stenosis $(\mathrm{OR}=1.02$, 
95\% CI: 1.01, 1.04). At younger paternal ages, each year increase in paternal age correlated with increased odds of having offspring with encephalocele, cataract, esophageal atresia, anomalous pulmonary venous return, and coarctation of the aorta, but these increased odds were not observed at older paternal ages. The effect of paternal age was modified by maternal age for gastroschisis, omphalocele, spina bifida, all orofacial clefts, and septal heart defects. Hence these findings suggested that paternal age may be a risk factor for some multifactorial birth defects. $^{20}$

A retrospective study was carried out in Nigeria to determine the prevalence of congenital malformations among newborns admitted in the neonatal unit of a tertiary teaching hospital in Enugu over a four year period from January 2007 to April 2011. Data was analyzed with SPSS. Seventeen out of a total of six hundred and seven newborn babies admitted in the newborn unit were found to have congenital abnormalities of various types, giving a prevalence of $2.8 \%$. Common abnormalities seen in these babies were mainly surgical birth defects and included cleft lip/cleft palate, neural tube defects (occurring either singly or in combination with other abnormalities), limb abnormalities (often in combination with neural tube defects of various types), omphalocoele, umbilical herniae, ano-rectal malformations and dysmorphism associated with multiple congenital abnormalities. The commonest forms seen were mainly surgical birth defects and include cleft lip/cleft palate and neural tube defects. ${ }^{21}$

A study was carried out in Japan over a period of six years from 2004 to 2010 in order to assess the association between maternal age and birth defects after the use of assisted reproductive technology. There were 219,185 pregnancies and 153,791 live births in total ART. Of these, 1943 abortions, stillbirths, or live births with birth defects were recorded. Multiple birth defects were observed among 14\% of the 25-29 year old class and $8 \%$ among other classes when chromosomal abnormalities were excluded. The prevalence of chromosomal abnormalities per pregnancy and per live birth became significantly and rapidly higher in mothers in the age classes of 30-35 and 40+ years. Non-chromosomal birth defects per pregnancy decreased linearly with advanced maternal age, while the number of non-chromosomal birth defects per live birth formed a gradual Ushaped distribution. The prevalence per pregnancy of congenital malformations of the nervous system was significantly lower with advanced maternal age. The relative risk per live birth was significant regarding congenital malformations of the circulatory system for a maternal age of 40+ years. Some other significant associations between maternal age and birth defects were observed. Hence it can be concluded that maternal age is associated with many of the birth defects. However older maternal age in itself does not have any extra risk for non-chromosomal birth defects. ${ }^{22}$

To determine if there is any relationship between medications used to treat nausea and vomiting of pregnancy and birth defects, a multi-site population based study was carried out using data from the National Birth Defects Prevention Study in the United States. Among the 4524 cases and 5859 controls included in the study, $67.1 \%$ reported first trimester NVP, and $15.4 \%$ of them reported using at least one agent for NVP. Nausea and vomiting of pregnancy was not associated with CP or NTDs, but modest risk reductions were observed for $\mathrm{CL} / \mathrm{P}$, and hypospadias ( $\mathrm{OR}=0.84,0.72-0.98$ ). In regards to treatments for NVP in the first trimester, the following adjusted associations were observed with an increased risk: proton pump inhibitors and hypospadias $(\mathrm{aOR}=4.36,1.21-15.81)$, steroids and hypospadias $(\mathrm{aOR}=2.87,1.03-7.97)$, and ondansetron and $\mathrm{CP}(\mathrm{aOR}=2.37$, 1.18-4.76), while antacids were associated with a reduced risk for CL/P (aOR=0.58, 0.38-0.89). The study concluded that Nausea and vomiting of pregnancy was not observed to be associated with an increased risk of birth defects, but possible risks related to three treatments (i.e. proton pump inhibitors, steroids and ondansetron), which could be chance findings, warrant further investigation. ${ }^{23}$

Prevalence of birth defects and risk factor analysis from a population based survey in Inner Mongolia, China conducted from 2005 to 2008 gave the following results: 976 children with birth defects were diagnosed. The prevalence rate of birth defects was 156.1 per 10000 births (95\%CI: 146.3-165.8). The prevalence rate of neural tube defect (20.1 per 10000 births) including anencephaly (6.9 per 10000), spina bifida (10.6 per 10000), and encephalocele (2.7 per 10000) was the highest, followed by congenital heart disease (17.1 per 10000). The relative risk (RR) for maternal age less than 25 was 2.22 (95\%CI: 2.05, 2.41). The RR of the ethnic Mongols was lower than Han Chinese (RR: 0.84; 95\%CI: 0.80-0.89). The RR of the third and second pregnancy was significantly higher than the first pregnancy while a slight difference between the second and the first pregnancy was also found. Alcohol drinking of mothers, familial inheritance and living area were also found to be related to the occurrence of the birth defects. Relatively higher birth defect rates were found in Inner Mongolia. This study found that maternal age less than 25, alcohol drinking, familiar inheritance, lower education level of mothers, times of pregnancies and living in rural areas may increase the risk of birth defects. Ethnic Mongols were less likely to have birth defects than Han Chinese. ${ }^{24}$

Prevalence and variations of birth defects in Korean Live Births were studied in the period 2005 to 2006. After the survey on birth defects was done in 2,348 medical institutions around the nation, the birth defect prevalence of livebirths in 2005-2006 was calculated.. The number of live births in Korea was 883,184 from 2005-2006, and 25,335 cases of birth defects were notified to the study, equivalent to a prevalence of 286.9 per 
10,000 live births. Anomalies of the circulatory system were the most common defects, accounting for $43.4 \%$ of birth defects with a prevalence of 124.5 per 10,000 live births. It was followed by the musculoskeletal system anomalies, the digestive system anomalies, and the urinary system anomalies. The five major birth defects based on the ranking of prevalence were atrial septal defect, ventricular septal defect, hydronephrosis, patent ductus arteriosus, and cleft lip/palate. Birth defects in live births were associated with a high proportion of low birth weight, prematurity, multiple births and advanced maternal age. ${ }^{25}$

A study was carried out to determine the racial or ethnic variations in the prevalence of selected major birth defects in Metropolitan Atlanta during the period 1994 to 2005 using data from the Metropolitan Atlanta registry. Compared with births to non-Hispanic white women, births to non-Hispanic black women had a significantly higher prevalence of five birth defects and a significantly lower prevalence of 10 birth defects, while births to Hispanic women had a significantly higher prevalence of four birth defects and a significantly lower prevalence of six birth defects. The racial/ethnic disparities in the prevalence of some defects varied by socio economic statuses, but no clear pattern emerged. Racial/ethnic disparities were suggested in $57 \%$ of included birth defects. Disparities in the prevalence of birth defects may result from different underlying genetic susceptibilities; exposure to risk factors; or variability in case diagnosis, ascertainment, or reporting among the subpopulations examined. ${ }^{26}$

To assess the risk of birth defects in offspring of men with a history of cancer, a cohort study using Danish and Swedish National Registries was carried out taking into the study all singleton children born alive in Denmark between 1994 and 2004 and in Sweden between 1994 and 2005 . Of the 8670 children with a paternal history of cancer, 8162 were conceived naturally and 508 were conceived using assisted reproductive technologies (ARTs) (in vitro fertilization or intracytoplasmatic sperm injection). Of the 17690795 children without a paternal history of cancer, 25926 were conceived using ARTs. Associations between paternal history of cancer and risk of adverse birth outcomes of children conceived naturally or by ARTs were investigated using log-linear binomial models. The offspring of male cancer survivors were more likely to have major congenital abnormalities than the offspring of fathers with no history of cancer $(\mathrm{RR}=1.17,95 \% \mathrm{CI}=1.05$ to $1.31, P=$ $.0043,3.7 \%$ vs $3.2 \%$ ). However, the mode of conception (natural conception or ARTs) did not modify the association between paternal history of cancer and risk of congenital abnormalities (natural conception, $\mathrm{RR}=$ $1.17,95 \% \mathrm{CI}=1.04$ to 1.31 ; $\mathrm{ARTs}, \mathrm{RR}=1.22,95 \% \mathrm{CI}=0.80$ to $1.87, P=.84$ ). The study concluded that there is a statistically significant but modest increase in the risk of major congenital abnormalities among offspring of males with a history of cancer, independent of the mode of conception. ${ }^{27}$

\section{Research Methodology}

\section{Research Question}

What is the spectrum of congenital anomalies among children attending the Departments of Pediatric Medicine and Surgery in Dhaka Medial College Hospital?

\section{Study Objectives \\ General Objective}

- To determine the spectrum of congenital anomalies among children attending the Departments of Pediatric Medicine and Surgery in Dhaka Medical College Hospital.

\section{Specific Objectives}

- To explore the variations of congenital anomalies occurring in children attending the Departments of Pediatric Medicine and Surgery in Dhaka Medical College Hospital.

- To understand the demographic trends regarding congenital anomalies in children.

- $\quad$ To describe the socioeconomic aspects of parents having children with congenital anomalies.

- To describe the antenatal and other maternal factors including patterns of diseases and infections in mothers having children with congenital anomalies.

- To investigate the outcomes of attending congenital anomaly patients. 


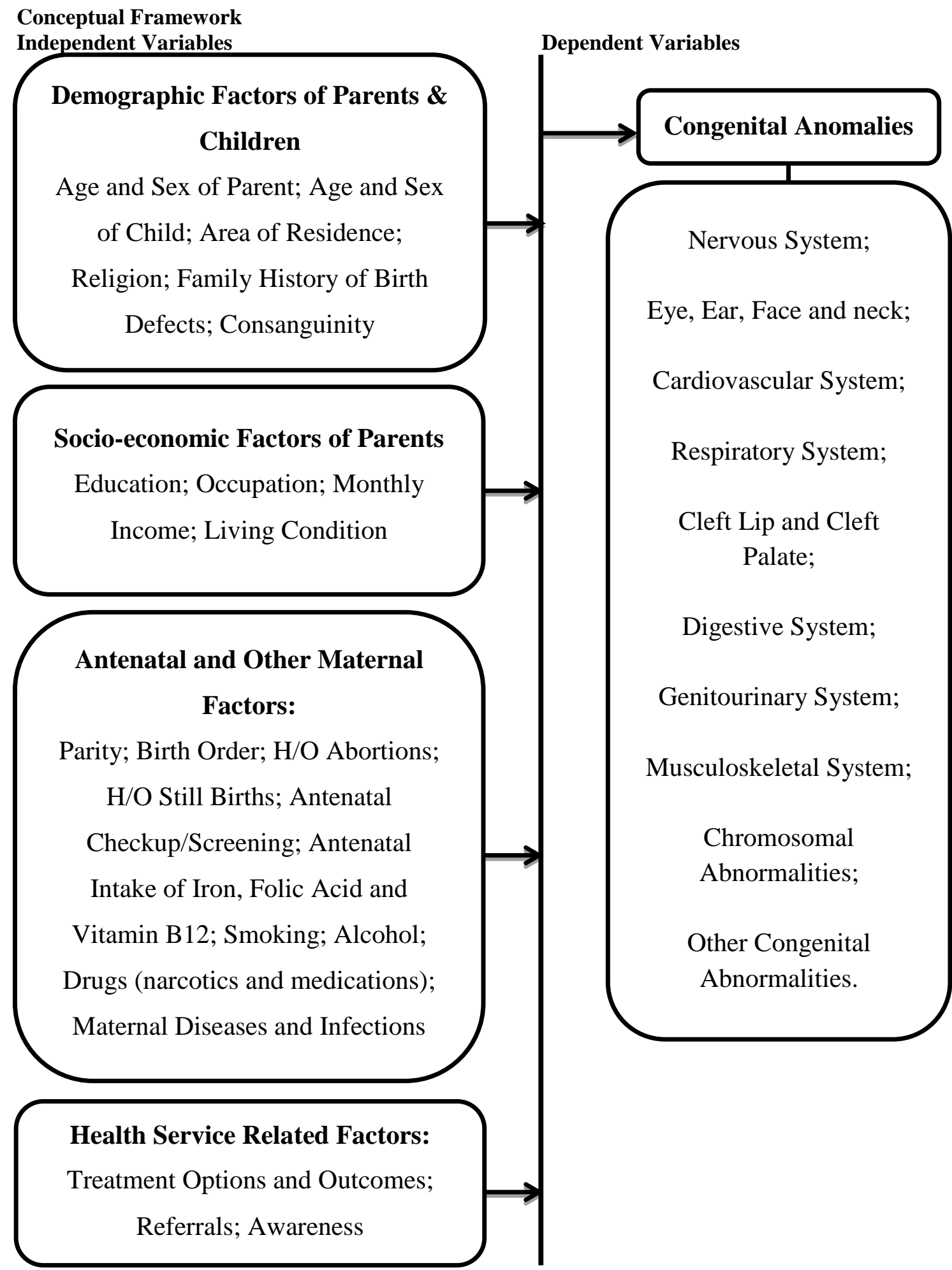

\section{Study Design}

A descriptive cross sectional study was carried out for the attainment of the above mentioned study objectives and to meet the constraints of resource, manpower and time.

Target Population\& Sample Population 
The target population included children with birth defects below the age of 15 years. And the sample population included children diagnosed with congenital anomalies below the age of 15 years whose mothers were present and were inclined to be interviewed, attending the Departments of Pediatric Medicine and Surgery of Dhaka Medical College Hospital.

\section{Study Site}

Departments of Pediatric Medicine and Surgery, Dhaka Medical College Hospital, Bangldadeesh.

\section{Study Period}

April,2013toOctober,2013

\begin{tabular}{|c|c|c|c|c|c|c|c|}
\hline \multirow{2}{*}{\multicolumn{8}{|c|}{$\begin{array}{l}\text { Activities } \\
\begin{array}{l}\text { Literature } \\
\text { review }\end{array}\end{array}$}} \\
\hline & & & & & & & \\
\hline \multicolumn{8}{|l|}{$\begin{array}{l}\text { Proposal } \\
\text { writing }\end{array}$} \\
\hline \multicolumn{8}{|l|}{$\begin{array}{l}\text { Data } \\
\text { collection }\end{array}$} \\
\hline \multicolumn{8}{|l|}{$\begin{array}{l}\text { Data } \\
\text { entry }\end{array}$} \\
\hline \multicolumn{8}{|l|}{$\begin{array}{l}\text { Data } \\
\text { analysis }\end{array}$} \\
\hline Draft report & & & & & & & \\
\hline $\begin{array}{l}\text { Final } \\
\text { submission }\end{array}$ & & & & & & & \\
\hline
\end{tabular}

\section{Sample Size}

Sample Size for a cross sectional study:

$n=\frac{Z^{2}\left(1-\frac{\alpha}{2}\right) p q}{d^{2}}$

$\mathrm{n}=$ Desired sample size

$\mathrm{Z}=$ Standard normal deviation

$\mathrm{p}=$ Anticipated population proportion $\mathrm{q}=(1-\mathrm{p})$

$\mathrm{d}=$ Allowable error

$\alpha=$ Level of significance

Estimation of sample size for this study:

$Z^{2}\left(1-\frac{\alpha}{2}\right)=1.96 \quad \mathrm{p}=3.7 \%$ or $0.037 \quad \mathrm{q}=(1-0.037)$ or $0.963 \quad \mathrm{~d}=2.25 \%$ or $0.0225 \alpha$ $=0.05$

$n=\frac{(1.96)^{2}(0.037)(0.963)}{(0.0225)^{2}}$

$=270$

Therefore the desired sample size was 270. To compensate for the uncertainties of losses of samples due unpredictable reasons, an additional $10 \%$ was added to the estimated sample size. Hence corrected sample size was 297.

During the actual process of data collection, estimated sample size could not be attained as time and patient turnover were constrained, for which data were collected from a total of 267 patients.

\section{Inclusion Criteria}

Children diagnosed with congenital anomalies below the age of 15 years whose mothers were present, were willing to participate, and were able to provide the required information, attending the Departments of Pediatric Medicine and Surgery of Dhaka Medical College Hospital.

\section{Sampling Technique}

Purposive sampling technique was applied for the study.

\section{Data Collection Tools}

Pre-tested questionnaire based on the objectives and variables were asked by oral interviews. The respondents were the mothers of the children having congenital anomalies.

\section{Data Management and Analysis}


The data collected were checked, edited, entered and analyzed using Statistical Package Social Science (SPSS) software version 17. Descriptive analysis of distributions and frequencies were carried out.

\section{Quality Control and Quality Assurance}

Consent forms, containing a clear explanation of the purpose and procedure of the study as well as privileges of the respondents were given and explained to the respondents prior interviewing.

Information sheets explaining the research in brief including instructions elucidating the process of questioning and recording of answers were given as well as explained to the research assistants and the data collectors.

The designed questionnaire was pretested in a pilot study in the Pediatric Department of Shahabuddin Medical College Hospital before going to the data collection field to check for acceptability, clarity of language, validity, reliability, accuracy of translation and quality of raw data and necessary corrections were made accordingly. During the entire time of the data collection process in Dhaka Medical College Hospital, the researcher (Dr. Chowdhury F. M. Bari) was present and supervised and monitored all aspects of the data collection process including day to day distribution of workload, examination of work performance and proof reading of all data. Errors detected were corrected immediately on site.

All steps of the research process were documented; including tools relied upon, raw observations and progress of research. Data were entered and processed weekly which included registration, editing, coding and computerization, preparation of dummy tables and statistical analysis of the data using SPSS. The final data were rechecked, analyzed and prepared.

\section{Ethical Considerations}

All ethical issues were considered as per guidelines of the Bangladesh Medical Research Council (BMRC) and World Health Organization (WHO). Permissions were taken from the administrative office of Dhaka Medical College Hospital as well as from the Departmental heads of Pediatric Surgery and Medicine. All interviews were conducted maintaining privacy with prior informed consents of respondents taken stating clearly the purpose and benefits of the study and freedom of refusal to participate. All the data collected were kept anonymous, maintaining confidentiality of all participants.

\section{Limitations of the study}

- This was a hospital based study encompassing a single hospital of Dhaka city. Even though this hospital is the sole largest hospital for the treatment of congenital anomalies, other specialized hospitals also account for a minor fraction of the CA cases especially cardiac anomalies, other complicated cases, and scattered cases of patients form upper class societies. Therefore the results from this study may not show a complete diversification of birth defects which may be present in the entire city.

- Sample size was limited for which results may not truly represent that of the wider city.

- A large fraction of birth defects end up as still births usually accounted for in the Obstetrics Department. This fraction could not be taken into the study as cases admitted or treated in the Pediatric Departments where the study was carried out include only live born children.

- Several variables especially those pertaining to maternal health such as maternal diseases and infections and many which are highly sensitive, relied on mothers' words as sufficient medical and demographic records were not available at the time of interview, for which an accurate picture may not have been obtained regarding these variables.

\section{Results}

This descriptive cross sectional study was carried out in order to determine the spectrum of congenital anomalies among 267 children with birth defects who attended the Departments of Pediatric Medicine and Surgery in Dhaka Medical College Hospital. The data obtained were analyzed to explore the variations of congenital anomalies occurring in children; to investigate the outcomes of congenital anomaly patients; to understand the demographic trends; to describe the socioeconomic aspects of their parents; to describe some of the antenatal and other maternal factors including life style factors and patterns of diseases and infections in mothers having children with birth defects. The findings of the study are documented in this section as follows:

Variations of congenital Anomalies

Distribution of congenital anomalies according to the body system or site 
Table 1: Distribution of congenital anomalies according to the body system/ site

\begin{tabular}{lll}
\hline Body system/site of congenital anomaly & Frequency & Percent \\
\hline Nervous system & 42 & 15.7 \\
Cardiovascular system & 26 & 9.7 \\
Respiratory system & 3 & 1.1 \\
Cleft lip and cleft palate & 18 & 6.7 \\
Digestive system & 72 & 27.0 \\
Genitourinary system & 42 & 15.7 \\
Musculoskeletal system & 40 & 15.0 \\
Other congenital malformations & 5 & 1.9 \\
Chromosomal abnormalities & 19 & 7.1 \\
\hline
\end{tabular}

A total of 267 patients diagnosed with congenital anomalies were studied. The distribution of congenital anomalies according to the body system or site is listed above.

Congenital anomalies pertaining to the digestive system accounted for majority of the cases $27 \%$ $(\mathrm{n}=72)$. Of digestive system anomalies, Hirschsprung's disease /aganglionosis / congenital (aganglionic) megacolonaccounted for most of the cases $(n=20)$, followed by other anorectal malformations $(n=12)$ and congenital absence, atresia and stenosis of anus with fistula $(n=8)$. Others included Congenital hypertrophic pyloric stenosis $(n=7)$; congenital absence, atresia and stenosis of small intestine $(n=6)$; neonatal intestinal obstruction $(n=5)$; congenital absence, atresia and stenosis of anus without fistula / imperforate anus $(n=5)$; congenital tracheo-esophageal fistula $(n=3)$; meconium ileus $(n=2)$; exomphalosomphalocele $(n=2)$; and congenital absence, atresia and stenosis of rectum without fistula / imperforate rectum $(n=2)$.

Nervous system accounted for $15.7 \%(n=42)$ of the total. Of the nervous system disorders, congenital hydrocephalus accounted for most of the cases $(n=23)$, followed by meningocele $(n=6)$ and meningomyelocele $(n=5)$. Also found were encephalocele $(n=4)$ and spina bifida $(n=4)$.

Congenital anomalies of the genitourinary system also accounted for $15.7 \%(n=42)$ of the cases. Of this hypospadias numbered most $(n=21)$, followed by undescended testicle $(n=6)$ and Congenital hydrocele $(n=4)$. Others included cloacal anomaly $(n=3)$; epispadias $(n=2)$; indeterminate sex, unspecified ambiguous genitalia $(=2)$; congenital posterior urethral valves $(n=2)$; and congenital hydronephrosis $(n=2)$.

Musculoskeletal system totaled to $15 \%$ (40) of the congenital anomalies. Gastroschisis $(n=16)$ accounted for most, followed by polydactyly $(n=12)$. Other musculoskeletal anomalies found included congenital umbilical hernia $(n=5)$; eventration of diaphragm $(n=4)$; and club foot $(n=3)$.

Cardiovascular congenital anomalies amounted to $9.7 \%(n=26)$. Ventricular septal defect $(n=8)$ was most common, followed by atrial septal defect $(n=7)$; tetralogy of fallot $(n=4)$; transposition of the great arteries $(n=3)$; and other congenital heart disease $(n=4)$.

$7.1 \%(n=19)$ of cases were chromosomal abnormalities, of which only 2 types were encountered, namely Down's syndrome $(n=11)$ and Turner's syndrome $(n=8)$.

Cleft lip and cleft palate accounted for $6.7 \%(n=18)$ while other congenital anomalies accounted for $1.9 \%(n=5)$. Of the other congenital anomalies, $1.9 \%(n=5)$, were cystic hgroma $(n=3)$ and conjoined twins $(\mathrm{n}=2)$.

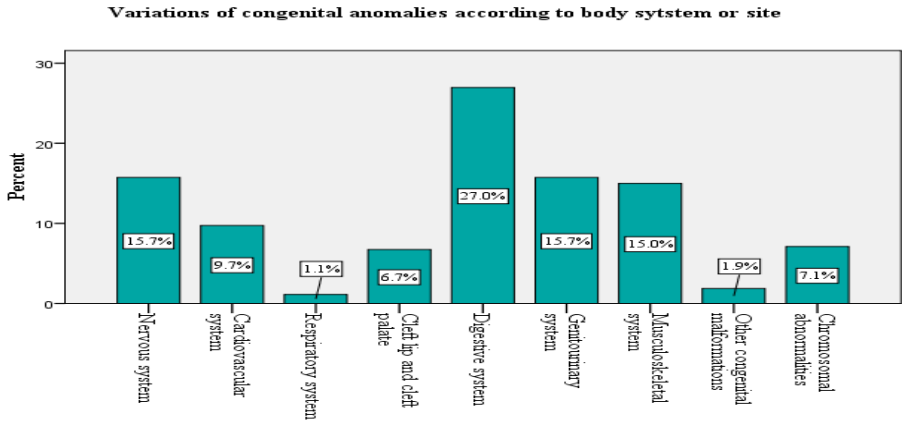

Figure 1: Distribution of congenital anomalies according to body system or site Distribution of congenital anomalies according to the specific types

Table 2: Types of congenital anomalies 
Spectrum of Congenital Anomalies among Children Attending the Pediatric Departments of Dhaka

\begin{tabular}{|c|c|c|}
\hline Nervous system: & & \\
\hline Congenital hydrocephalus & 23 & 8.6 \\
\hline Meningocele & 6 & 2.2 \\
\hline Encephalocele & 4 & 1.5 \\
\hline Meningomyelocele & 5 & 1.9 \\
\hline Spina Bifida & 4 & 1.5 \\
\hline \multicolumn{3}{|l|}{ Cardiovascular system: } \\
\hline Ventricular septal defect & 8 & 3.0 \\
\hline Atrial septal defect & 7 & 2.6 \\
\hline Tetralogy of Fallot & 4 & 1.5 \\
\hline Other congenital heart diseases & 4 & 1.5 \\
\hline Transposition of the Great Arteries & 3 & 1.1 \\
\hline \multicolumn{3}{|l|}{ Respiratory system: } \\
\hline Choanal atresia & 3 & 1.1 \\
\hline \multicolumn{3}{|l|}{ Cleft lip and cleft palate: } \\
\hline Cleft lip/palate & 18 & 6.7 \\
\hline \multicolumn{3}{|l|}{ Digestive system: } \\
\hline Hirschsprung's disease / Aganglionosis / Congenital (aganglionic) megacolon & 20 & 7.5 \\
\hline Other Anorectal Malformations & 12 & 4.5 \\
\hline Congenital absence, atresia and stenosis of anus with fistula & 8 & 3.0 \\
\hline Congenital hypertrophic pyloric stenosis & 7 & 2.6 \\
\hline Congenital absence, atresia and stenosis of small intestine & 6 & 2.2 \\
\hline Congenital absence, atresia and stenosis of anus without fistula / Imperforate anus & 5 & 1.9 \\
\hline Neonatal Intestinal Obstruction & 5 & 1.9 \\
\hline Congenital tracheo-esophageal fistula & 3 & 1.1 \\
\hline Meconium ileus & 2 & 0.7 \\
\hline ExomphalosOmphalocele & 2 & 0.7 \\
\hline Congenital absence, atresia and stenosis of rectum without fistula / Imperforate rectum & 2 & 0.7 \\
\hline \multicolumn{3}{|l|}{ Genitourinary system: } \\
\hline Hypospadias & 21 & 7.9 \\
\hline Undescended testicle & 6 & 2.2 \\
\hline Congenital hydrocele & 4 & 1.5 \\
\hline Epispadias & 2 & .7 \\
\hline Cloacal anomaly & 3 & 1.1 \\
\hline Indeterminate sex, unspecified Ambiguous genitalia & 2 & 0.7 \\
\hline Congenital posterior urethral valves & 2 & 0.7 \\
\hline Congenital hydronephrosis & 2 & 0.7 \\
\hline \multicolumn{3}{|l|}{ Musculoskeletal system: } \\
\hline Gastroschisis & 16 & 6.0 \\
\hline Polydactyly & 12 & 4.5 \\
\hline Congenital umbilical hernia & 5 & 1.9 \\
\hline Eventration of diaphragm & 4 & 1.5 \\
\hline Club Foot & 3 & 1.1 \\
\hline \multicolumn{3}{|l|}{ Other congenital malformations: } \\
\hline Cystic Hygroma & 3 & 1.1 \\
\hline Conjoined Twins & 2 & 0.7 \\
\hline \multicolumn{3}{|l|}{ Chromosomal abnormalities: } \\
\hline Down's syndrome & 11 & 4.1 \\
\hline Turner's syndrome & 8 & 3.0 \\
\hline Total & 267 & 100.0 \\
\hline
\end{tabular}

Out of the 267 cases of congenital anomalies, congenital hydrocephalus was the most common accounting for $8.6 \%(\mathrm{n}=23)$ of the cases. This was followed by hypospadias $7.9 \%(\mathrm{n}=21)$; Hirschsprung's disease /aganglionosis / congenital (aganglionic) megacolon 7.5\% ( $\mathrm{n}=20)$; cleft lip/palate 6.7\% ( $\mathrm{n}=18)$; gastroschisis $6 \%(n=16)$; other anorectal malformations $4.5 \% \quad(n=12)$; polydactyly $4.5 \% \quad(n=12)$; down's 
syndrome $4.1 \%(n=11)$; ventricular septal defect $3 \%(n=8)$; congenital absence, atresia and stenosis of anus with fistula 3\% (n=8);Turner's syndrome 3\% $(n=8)$; congenital hypertrophic pyloric stenosis $2.6 \%(n=7)$; atrial septal defect 2.6\% ( $n=7)$; meningocele 2.2\% ( $n=6)$; congenital absence, atresia and stenosis of small intestine $2.2 \%$ $(\mathrm{n}=6)$; undescended testicle $2.2 \%(\mathrm{n}=6)$; congenital umbilical hernia $1.9 \%(\mathrm{n}=5)$; neonatal intestinal obstruction $1.9 \%(n=5)$; congenital absence, atresia and stenosis of anus without fistula / imperforate anus $1.9 \%(n=5)$; meningomyelocele $1.9 \%(n=5)$; encephalocele $1.5 \%(n=4)$; spina bifida $1.5 \%(n=4)$; tetralogy of Fallot $1.5 \%$ $(\mathrm{n}=4)$; other congenital heart diseases $1.5 \%(\mathrm{n}=4)$; congenital hydrocele $1.5 \%(\mathrm{n}=4)$; eventration of diaphragm $1.5 \%(n=4)$; cystic hygroma $1.1 \%(n=3)$; club foot $1.1 \%(n=3)$; cloacal anomaly $1.1 \%(n=3)$; congenital tracheoesophageal fistula $1.1 \%(\mathrm{n}=3)$; choanal atresia $1.1 \%(\mathrm{n}=3)$; transposition of the great arteries $1.1 \%(\mathrm{n}=3)$; meconium ileus $0.7 \%(n=2)$; exomphalosomphalocele $0.7 \%(n=2)$; congenital absence, atresia and stenosis of rectum without fistula / imperforate rectum $0.7 \%(\mathrm{n}=20$; epispadias $0.7 \%(\mathrm{n}=2)$; indeterminate sex, unspecified ambiguous genitalia $0.7 \%(n=2)$; congenital posterior urethral valves $0.7 \%(n=2)$; congenital hydronephrosis $0.7 \%(n=2)$; and conjoined twins $0.7 \%(n=2)$.

\section{Outcomes of attending congenital anomaly patients Treatment outcomes}

Out of 267 patients with congenital anomaly attending the Departments of Pediatric Surgery and Medicine of Dhaka Medical College Hospital, 71.9\% (192) of them were treated and discharged with correction of anomaly. $6.7 \%(\mathrm{n}=18)$ were discharged without correction of anomalies which mainly included patients with chromosomal anomalies. 18. $4 \%(n=49)$ were referred to higher centers. And 3\% $(n=8)$ of the patients died during hospital stay.

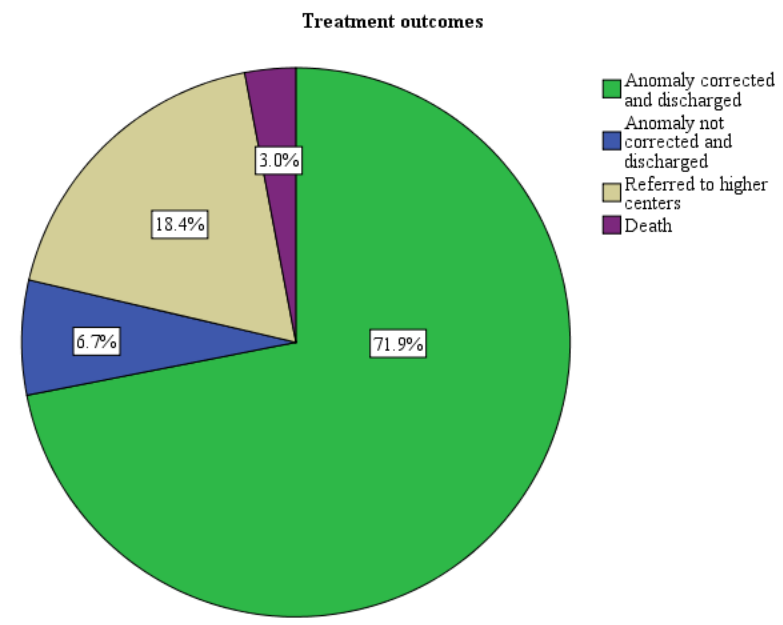

Figure 2: istribution of patients by treatment outcome

\section{Referrals}

Out of all the patients, $82 \%$ were treated in Dhaka Medical College Hospital. $9.4 \%$ were referred to National Institute of Cardiovascular Diseases, Bangladesh (NICDB).all of which were cases of congenital heart diseases $(n=25) .7 .9 \%$ of the patients were referred to Dhaka Sishu (Children's) Hospital which included 3 cases of congenital tracheo-esophageal fistula; 6 cases of congenital absence, atresia and stenosis of small intestine; and all cases $(n=16)$ of gastroschisis. And $0.7 \%$ of cases namely 2 cases of conjoined twins were referred to Bangabandhu Sheikh Mujib Medical University Hospital. 


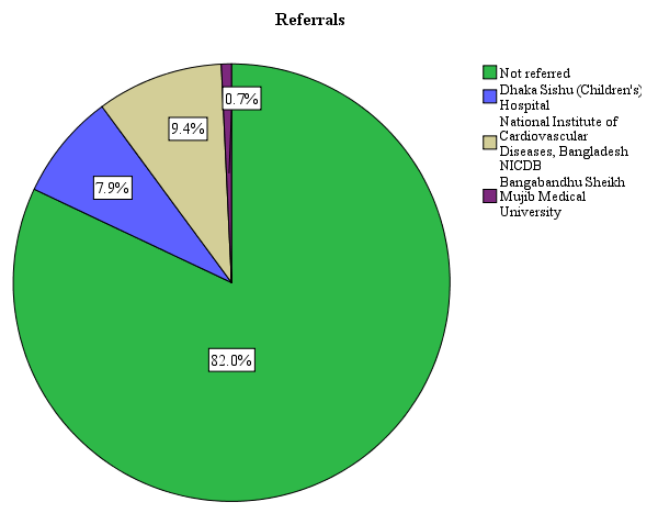

Figure 3: Distribution by Referral

\section{Congenital anomalies that resulted in death of in-hospital patients}

8 patients died during hospital stay of which 4 were diagnosed with encephalocele, 3 with neonatal intestinal obstruction, and 1 with ventricular septal defect.

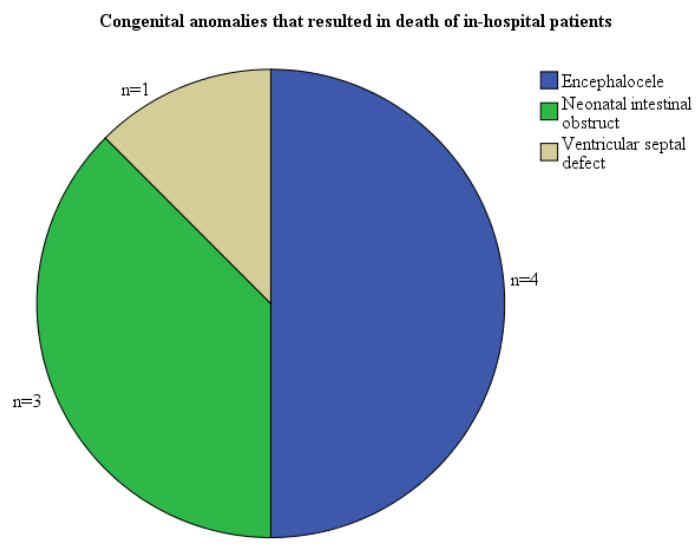

Figure 4: Distribution of congenital anomalies that resulted in deaths of in-hospital patients

\section{Demographic factors}

\section{Age groups of patients}

Table 3: Distribution of patients by age group

Of the children diagnosed with congenital anomalies, the age groups of children at the time of seeking medical help were recorded as follows: early neonates (1-7 days) accounted for $33.3 \%(\mathrm{n}=89)$ of cases; late neonate (827 days), $15.4 \%$ ( $n=41)$; post neonate (28 days to 1 year), 24.7\% ( $n=66)$; Preschool (1-4 years), 19.1\% ( $n=51)$; and school (5-14 years), $7.5 \%(n=20)$.

Sex distribution of patients

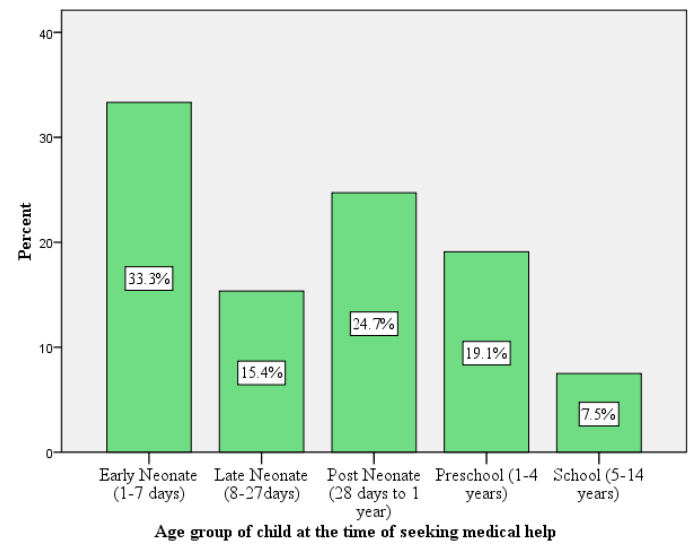

Figure 5: Distribution of patients by age group 
Out of 267 patients, $52.8 \%(n=141)$ were male, $46.4 \%(n=124)$ were female and $0.7 \%(n=2)$ had ambiguous genitalia.

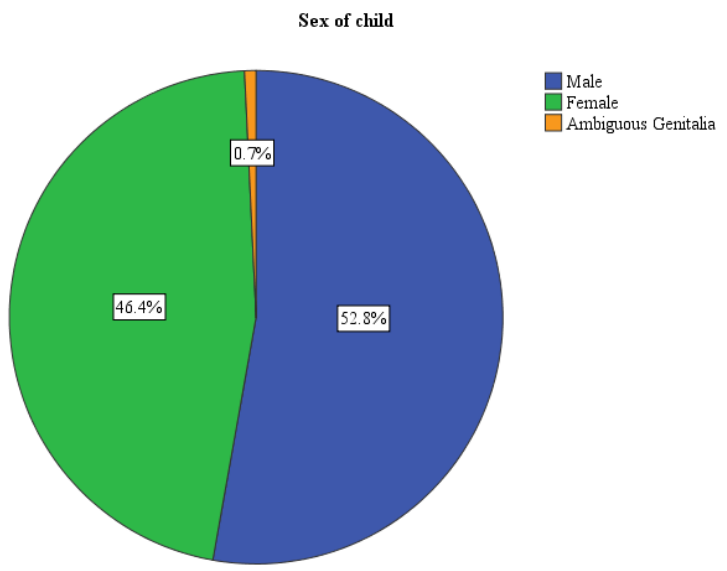

Figure 6: Distribution of patients by sex

\section{Division/District of residence of patients}

Majority of the patients came from Dhaka division, 33.3\% ( $\mathrm{n}=89)$, followed by Khulna Division, 14.2\% ( $n=38)$; Barisal Division, 13.1\% ( $n=35)$; Rangpur Division, 12.7\% ( $n=34)$; Chittagong Division, $12.4 \%$ $(\mathrm{n}=33)$, Rajshahi Division, 8.6\% $(\mathrm{n}=23)$; and Sylhet Division, 5.6\% $(\mathrm{n}=15)$.Dhaka division recorded the following distribution ofdistricts of respondents: Dhaka $(n=20)$, Tangail( $n=9)$, Gazipur(n=7), Manikganj ( $n=6)$; Kishoreganj ( $n=5)$, Narsingdi $(n=5)$, Rajbari $(n=5)$, Shariatpur $(n=5)$, Munshiganj $(n=4)$, Narayanganj $(n=4)$, Netrakona(n=4), Sherpur ( $n=4)$, Jamalpur $(n=3)$, Mymensingh $(n=3)$, Faridpur $(n=2)$, Madaripur $(n=2)$ and Gopalganj $(n=1)$.Khulna Division included: Bagerhat $(n=7)$, Jessore $(n=7)$, Magura $(n=6)$, Jhenaidah $(n=5)$, Khulna ( $n=3)$, Kushtia $(n=3)$, Chuadanga( $n=2)$ and Meherpur $(n=2)$. Barisal Division included: Barisal $(n=10)$, Bhola ( $n=10)$, Barguna( $n=6)$, Pirojpur $(n=4)$, Jhalokati $(n=3)$ andPatoakhali $(n=2)$. Rangpur Division included: Rangpur ( $n=10)$,Nilphamari( $n=6)$, Gaibandha $(n=5)$, Kurigram $(n=5)$, Thakurgaon $(n=3)$, Dinajpur $(n=2)$, Panchagarh $(n=2)$ and Lalmonirhat $(n=1)$. Chittagong Division included: Comilla $(n=8)$, Chittagong $(n=8)$, Feni $(n=6)$, Brahmanbaria $(n=4)$, Bandarban $(n=1)$, Cox's Bazar $(n=1)$,Khagrachhari $(n=1)$, Lakshmipur $(n=1)$ and Noakhali $(n=1)$.Rajshahi Division included: Joypurhat $(n=6)$, Naogaon $(n=4)$, Pabna $(n=4)$, Satkhira $(n=3)$, Natore $(n=3)$, Rajshahi $(n=3)$ and Sirajganj $(n=3)$. Sylhet Division included: Moulvibazar $(n=4)$, Sunamganj $(n=4)$, Sylhet $(n=4)$ and Habiganj $(n=3)$.

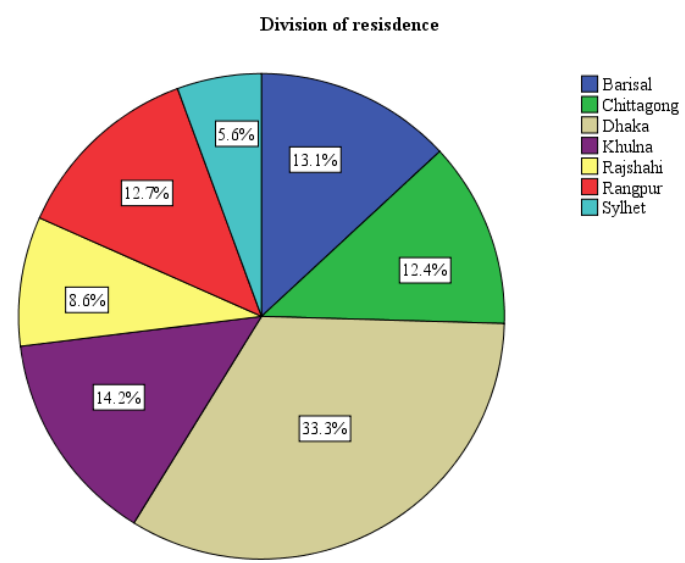

Figure 7: Distribution of respondents by division of residence

\section{Religion}


$92 \%(n=245)$ of the respondents were Muslims, with Hindus $6.4 \%(n=17)$, Christians $1.5 \%(n=4)$ and Buddhist $0.4 \%(n=1)$. None were found to be atheists or of mixed or other religious groups.

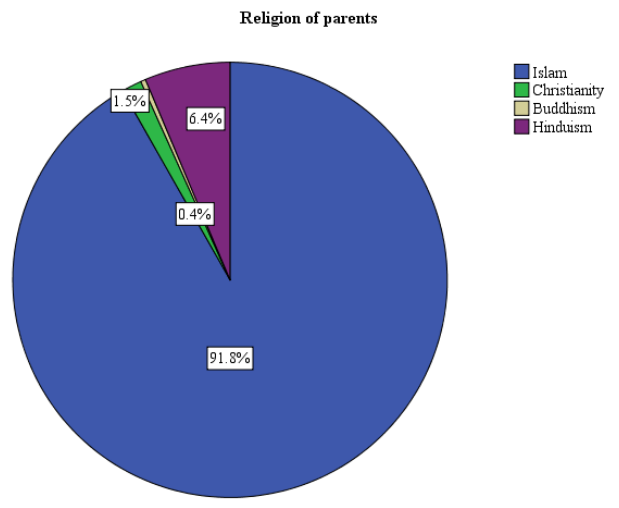

Mother's age group

Figure 8: Distribution of respondents by religion

Majority of the mothers were in age group of 21-25 years with $44.9 \%(n=120)$. This was followed by the 26-30 year group $22.1 \%(n=59), 16-20$ years $16.9 \%(n=45), 31-35$ years $12.4 \%(n=33)$ and lastly 36 years and above $3.7 \%(n=10)$.

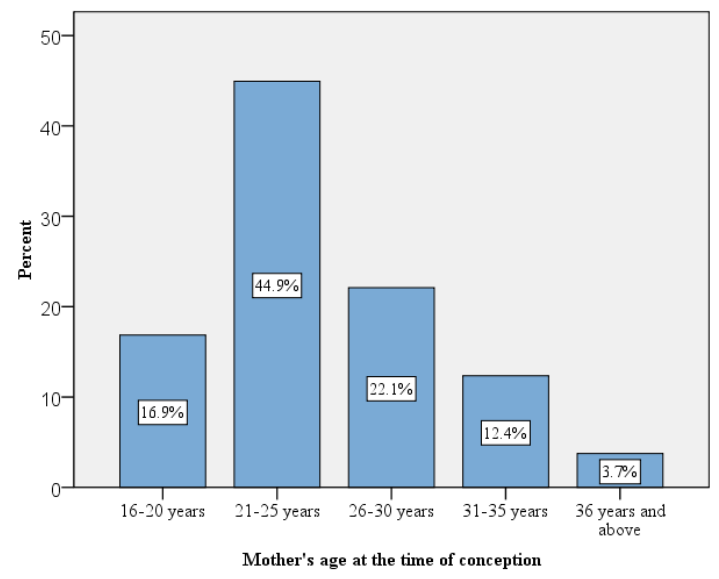

Figure 9: Distribution of mothers by age group

\section{Father's age group}

$55.4 \%(\mathrm{n}=148)$ of the fathers were in the age group $25-34$ years; $29.6 \%(\mathrm{n}=79)$ were $35-44$ years, $11.2 \%(\mathrm{n}=30)$ were $45-54$ years, $3 \%(n=8)$ were $15-24$ years and $0.7 \%(n=2)$ was $55-64$ years.

Family history of birth defects

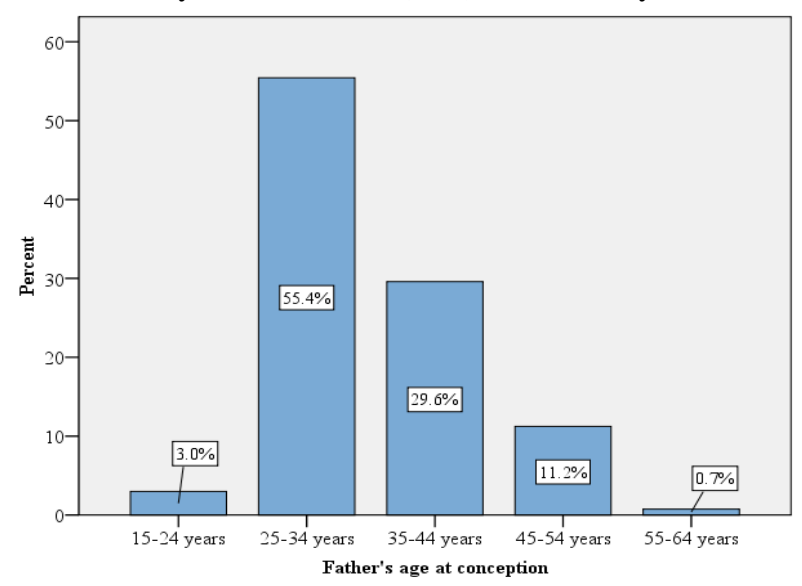

Figure 10: Distribution of fathers by age group 
$94 \%$ of the patients did not report of any family history of birth defects. $6 \%$ reported of birth defects in some members of the family. The types of congenital anomalies that were present in those patients with a positive family history were as follows: hypospadias $(n=4)$; congenital hypertrophic pyloric stenosis $(n=2)$ meningocele $(n=2)$; cleft lip/cleft palate $(n=2)$; undescended testicles $(n=2)$; coacal anomaly $(n=1)$; Down's syndrome $(n=1)$; Turner's syndrome $(n=1)$ and other congenital heart disease $(n=1)$.

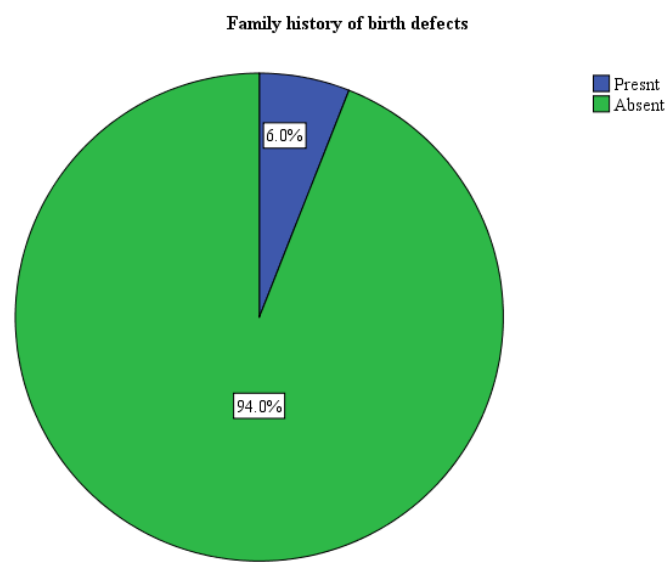

Figure 11: Distribution of patients by family history of birth defect

\section{Consanguinity}

$96.6 \%(n=258)$ of the parents had non consanguineous marriages. Consanguinity was observed among $3.4 \%(n=9)$ of which all were between distant relatives or cousins.

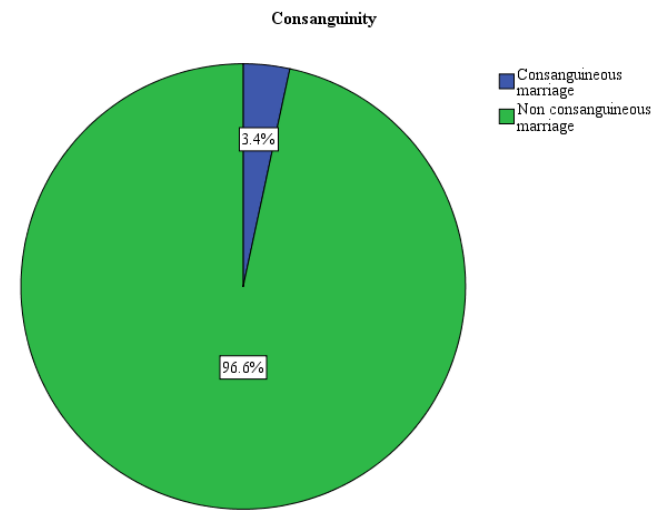

Figure 12: Distribution of respondents by consanguinity

Table 3: Congenital anomalies observed with consanguineous marriages

\begin{tabular}{llc}
\hline Congenital anomalies with consanguineous marriage & Frequency & Percent $(\%)$ \\
\hline Down's syndrome & 1 & 11.1 \\
Epispadias & 1 & 11.1 \\
Hypospadias & 2 & 22.2 \\
Indeterminate sex / Ambiguous genitalia & 1 & 11.1 \\
Tetralogy of Fallot & 1 & 11.1 \\
Undescended testicle & 2 & 22.2 \\
Ventricular septal defect & 1 & 11.1 \\
Total & 9 & 100.0 \\
\hline
\end{tabular}

The patients with congenital anomalies having consanguineous parents showed the following pattern of anomalies: hypospadias $(n=2)$, undescended testicles $(n=2)$, Down's syndrome $(n=1)$, epispadias $(n=1)$, indeterminate sex / ambiguous genitalia $(n=1)$, tetralogy of Fallot $(n=1)$ and ventricular septal defect $(n=1)$.

\section{Socioeconomic factors}

Mothers' educational levels 
$40.4 \%(n=108)$ of the mothers had primary or some school level education (up to or below $6^{\text {th }}$ grade). $30.3 \%$ $(\mathrm{n}=81)$ had education up to secondary school (up to $10^{\text {th }}$ grade); $19.5 \%(\mathrm{n}=52)$ were illiterate (no formal education); $3.7 \%(\mathrm{n}=10)$ completed higher secondary school (up to college/12 ${ }^{\text {th }}$ grade); $3 \%(\mathrm{n}=8) \mathrm{had}$ undergraduate level education; $1.9 \%(\mathrm{n}=5)$ had some undergraduate education or vocational degrees; and $1.1 \%$ had $(n=3)$ had post graduate level education.

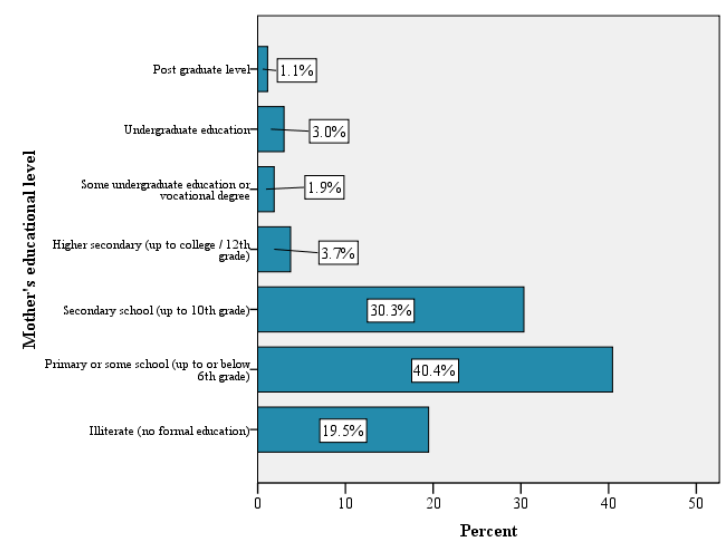

Figure 13: Mothers' educational levels

Fathers' educational levels

$32.2 \%$ ( $n=86$ ) of the fathers had primary or some school level education (up to or below $6^{\text {th }}$ grade). $31.5 \%(n=84)$ had education up to secondary school (up to $10^{\text {th }}$ grade); $16.1 \%(n=43)$ were illiterate (no formal education); $12.7 \%(\mathrm{n}=34)$ completed higher secondary school (up to college/12 ${ }^{\text {th }}$ grade); $3.7 \%(\mathrm{n}=10)$ had undergraduate level education. $2.6 \%(\mathrm{n}=7)$; had some undergraduate education or vocational degrees; and $1.1 \%$ $(n=3)$ had post graduate level education.

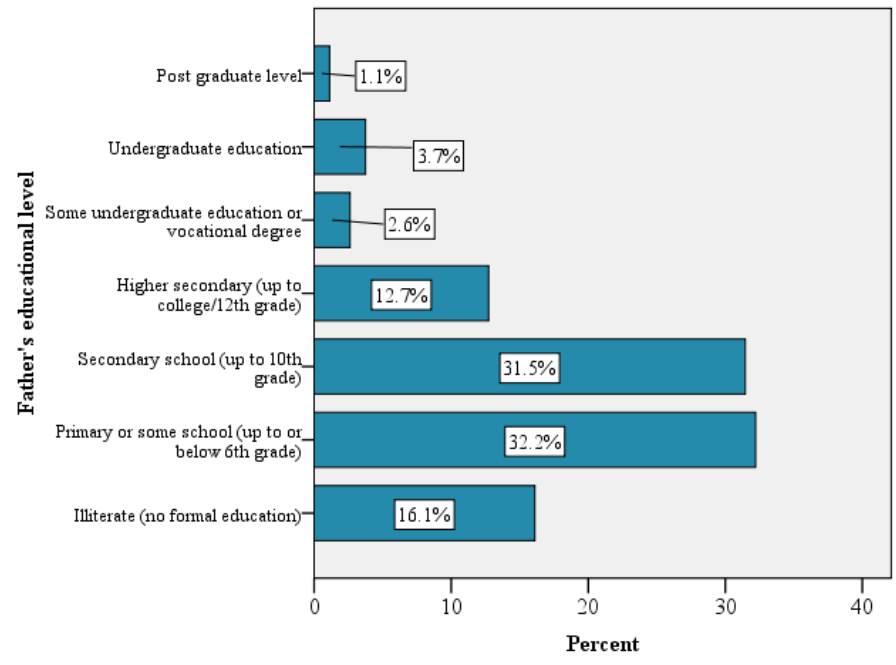

Figure 14: Father's educational levels

\section{Mothers' occupations}

Majority of mothers, $72.3 \%(n=193)$, were house wives; $12.7 \%(n=34)$ were farmers; $9.7 \%(n=26)$ had clerical or technical jobs; $3 \%(n=8)$ were hard laborers; $1.9 \%(n=5)$ were house maids; and $0.4 \%(n=1)$ held professional or administrative job. 


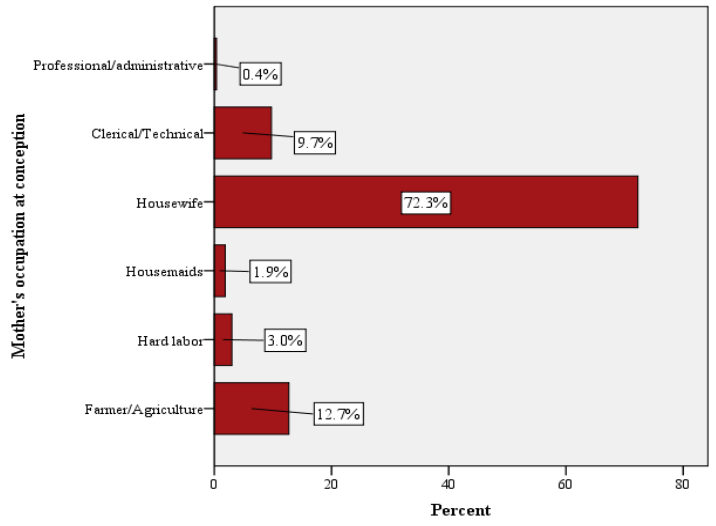

Figure 15: Mothers' occupations

\section{Fathers' occupations}

$46.8 \%(n=125)$ of the fathers held clerical or technical jobs; $25.5 \%(n=68)$ were farmers; $13.1 \%(n=35)$ were hard laborers; $12.4 \%(\mathrm{n}=33)$ were involved in business; $1.9 \%(\mathrm{n}=5)$ had professional or administrative jobs; and $0.4(n=1)$ had other occupations.

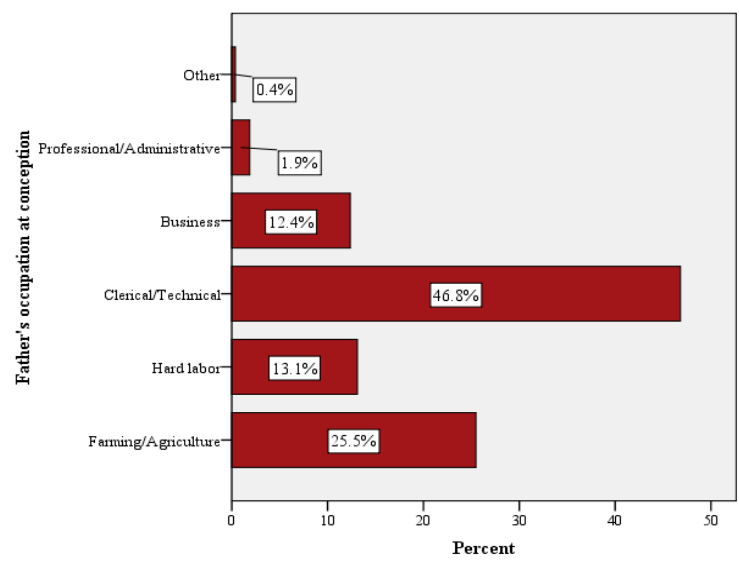

Figure 16: Fathers' occupations

Family income

Vast majority, 58.4\% ( $\mathrm{n}=156)$, of the families having children with congenital anomaliesearned 5,0009,999 Takas (62-125 USD as per average September 2013 conversion rate of $1 \$=80$ Takas) per month; 30.3\% $(\mathrm{n}=81)$ of families earned 10,000-24,999 Takas (125-312 USD); 6\% ( $\mathrm{n}=16)$ earned 2,500-4,999 Takas (31-62 USD); $3.7 \%(n=10)$ earned 25,000-49,999 Takas (312-625 USD); 0.7\% $(n=2)$ earned less than 2500 Takas $(<31$ USD); $0.4 \%(\mathrm{n}=1)$ earned 50,000-74,999 Takas (625-938 USD); and 0.4\% $(\mathrm{n}=1)$ earned above 75,000 Takas (>938 USD).

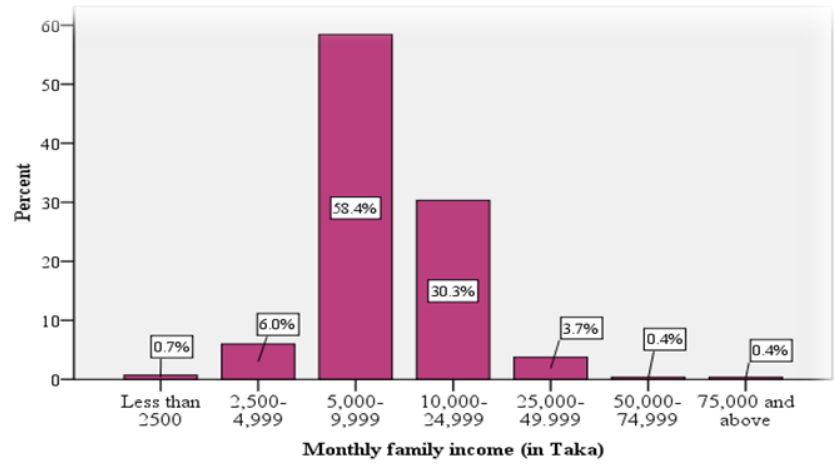

Types of Residences

Figure 17: Monthly family income 
Most of the respondents, $41.2 \%(n=110)$ reported living in rural mud (kacha) type of housing; $38.6 \%(n=103)$ lived in rural brick (paka) type of housing; 15.4\% ( $\mathrm{n}=41)$ lived in urban planned or cramped housing; $4.5 \%$ $(n=12)$ lived in urban planned housing or residential areas; while $0.4 \%(n=1)$ reported living in slums.

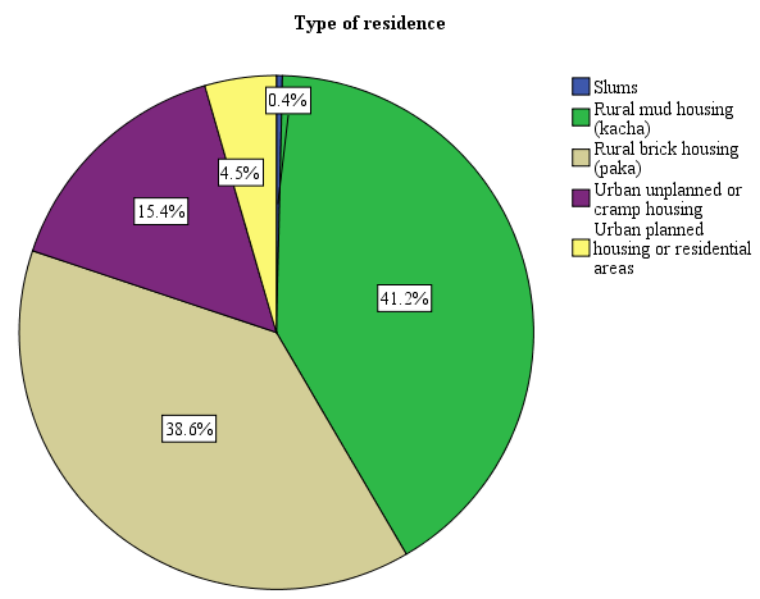

Figure 18: Types of residences

\section{House hold features}

Respondents were asked to pick the highest ranked house hold feature that was present in their residence from a range of house hold features that corresponded to the living standards. These features include from lowest to highest, pit-hole latrines, sanitary latrines, modern toilets, electricity, television (TV), computer and air conditioning (AC). Only $0.7 \%(\mathrm{n}=2)$ of the respondents picked air conditioning as their highest ranked household feature. $3.4 \%(n=9)$ picked computer which was the second ranked feature in the list. $40.1 \%(n=107)$ picked television as their highest ranked feature which was third on the list. $53.6 \%(\mathrm{n}=143)$ picked electricity which was fourth on the list. $1.1 \%(\mathrm{n}=3)$ had only sanitary latrines and pit holes latrines as their highest ranked household features which were at the bottom of the list.

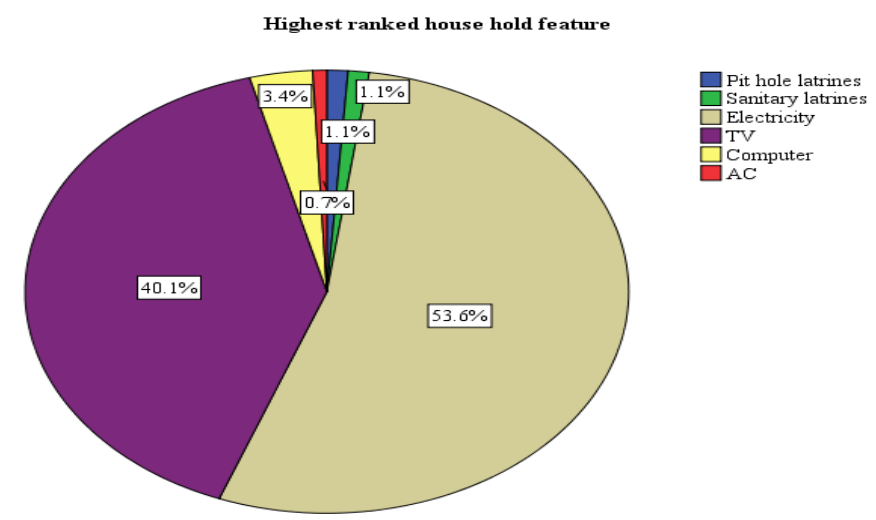

Figure 19: Distribution by highest ranked house hold feature 
Table 4: Distribution by parity, birth order, history of abortions and still births

\begin{tabular}{|c|c|c|}
\hline & Frequency & Percent (\%) \\
\hline \multicolumn{3}{|l|}{ Parity } \\
\hline 1 & 45 & 16.9 \\
\hline 2 & 80 & 30.0 \\
\hline 3 & 79 & 29.6 \\
\hline 4 & 54 & 20.2 \\
\hline 5 and above & 9 & 3.4 \\
\hline \multicolumn{3}{|c|}{ Birth order of child } \\
\hline $1 \mathrm{st}$ & 54 & 20.2 \\
\hline 2nd & 74 & 27.7 \\
\hline $3 r d$ & 78 & 29.2 \\
\hline 4th & 56 & 21.0 \\
\hline 5 th or above & 5 & 1.9 \\
\hline \multicolumn{3}{|c|}{ History of abortions } \\
\hline Yes & 23 & 8.6 \\
\hline No & 244 & 91.4 \\
\hline \multicolumn{3}{|c|}{ History of still births } \\
\hline Yes & 11 & 4.1 \\
\hline No & 256 & 95.9 \\
\hline
\end{tabular}

Antenatal checkups/screenings (ANC visits)

$41.9 \%(n=112)$ of the mothers had no antenatal care visits; $43.1 \%(n=115)$ had irregular visits; while only $15 \%(\mathrm{n}=40)$ had regular antenatal checkups/screening.

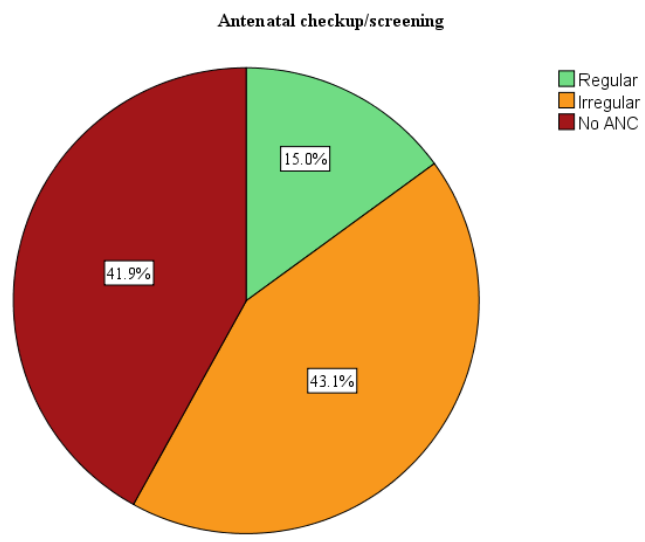

Figure 20: Distribution of mothers by antenatal checkup/screening (ANC visit)

Antenatal intake of iron, folic acid and vitamin B12

Out of 267 respondents, $69.3 \%(n=185)$ did not take iron, folic acid and vitamin B12 during pregnancy. $30.7 \%$ $(\mathrm{n}=82)$ took iron, folic acid and vitamin B12 supplementation during pregnancy. 


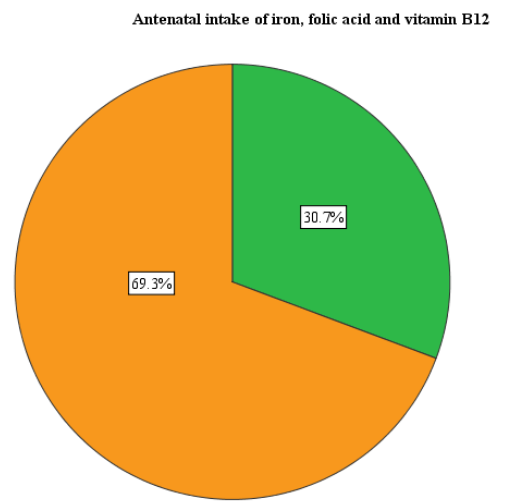

$\underset{\square}{\square}$ Nos

Figure 21: Distribution of mothers by antenatal intake of iron, folic acid and vitamin B12

\section{Smoking during pregnancy}

Majority of the mothers, $90.6 \%$ ( $\mathrm{n}=242)$, did not report of any smoking habits during pregnancy. $9.4 \%$ $(\mathrm{n}=25)$ were passive smokers with fathers being smokers in all the cases of passive smoking. None were found to be active smokers.

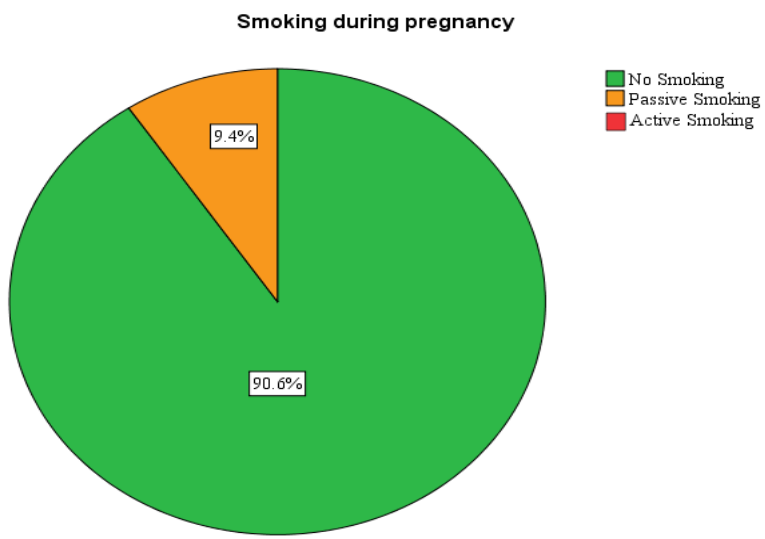

Figure 22: Distribution of mothers by smoking habits during pregnancy

\section{Drugs or medications taken during pregnancy}

Table 5: Distribution by antenatal intake of drugs or medications

\begin{tabular}{lrr}
\hline \multicolumn{1}{c}{ Drugs/medications taken during pregnancy } & Frequency & Percent (\%) \\
\hline Antihypertensive & 8 & 3.0 \\
Antiepileptic & 2 & 0.7 \\
Oral Hypoglycemic & 3 & 1.1 \\
Antibiotic (unspecified) & 7 & 2.6 \\
Anti-asthmatic & 1 & .4 \\
None & 201 & 75.3 \\
Not known & 39 & 14.6 \\
Others & 6 & 2.2 \\
\hline
\end{tabular}

$75.1 \%(n=201)$ did not report of taking any drugs or medications during pregnancy. $14.6 \%(n=39)$ did not know if any medications were taken during pregnancy. $3.0 \%(n=8)$ reported of taking antihypertensive drugs. $2.6 \%$ $(\mathrm{n}=7)$ reported of taking antibiotics but could not specify the name of antibiotics. $2.2 \%(\mathrm{n}=6)$ took some kind of medication but were unable to specify. $1.1 \%(\mathrm{n}=3)$ reported of taking oral hypoglycemic drugs. $0.7 \%(\mathrm{n}=2)$ took antiepileptic drugs. And $0.4 \%(\mathrm{n}=1)$ took some kinds of anti-asthmatic drugs. Congenital anomalies observed with maternal intake of antihypertensive included congenital absence, atresia and stenosis of anus with fistula; undescended testicle; congenital umbilical hernia; gastroschisis; and conjoined Twins. Anomalies observed with antibiotics included congenital hydrocephalus; hypospadias; Down's syndrome; neonatal intestinal obstruction; meningocele; and cleft lip/palate. Those with oral hypoglycemic included spina 
bifida,gastroschisis and polydactyly. With antiepileptic, congenital hydrocephalus and Down's syndrome were observed. Ambiguous genitalia was observed in a patient with mother who took anti-asthamitic.

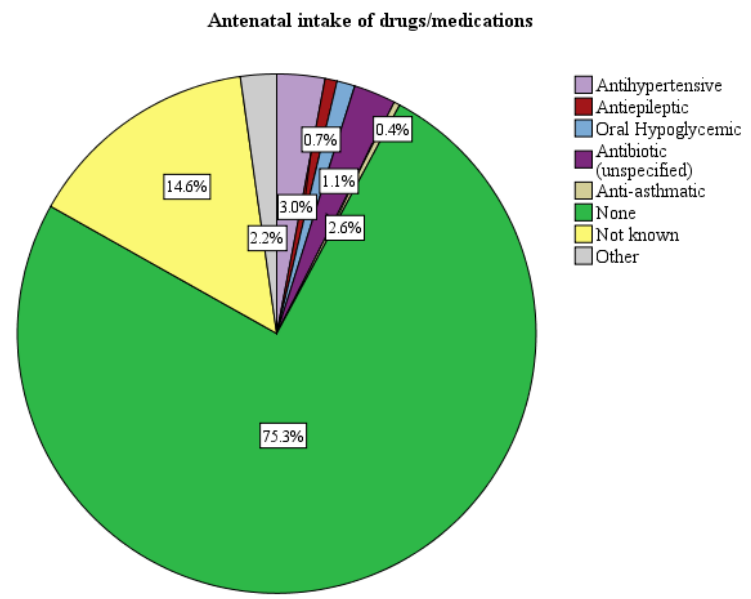

Figure 23: Distribution of mothers by antenatal intake of drugs or medications

Maternal diseases and infections during pregnancy

Table 6: Distribution by maternal diseases and infections during pregnancy

\begin{tabular}{lll}
\hline & Frequency & Percent $(\boldsymbol{\%})$ \\
\hline Maternal diseases during pregnancy & & 3.0 \\
Diabetes & 8 & 3.4 \\
Hypertension & 9 & 1.1 \\
Epilepsy & 3 & 88.4 \\
None & 236 & 3.0 \\
Not known & 8 & 1.1 \\
Asthma & 3 & \\
Maternal infections during pregnancy & & 80.1 \\
None & 214 & 19.9 \\
\hline Not known & 53 & \\
\hline
\end{tabular}

$88.4 \%(n=236)$ of the respondents did not report of having any disease during pregnancy while the disease status of $3 \%(n=8)$ were not known. $3.4 \%(n=9)$ reported of having hypertension during pregnancy; $3 \%(n=8)$ were diabetic; $1.1 \%(\mathrm{n}=3)$ had epilepsy; and $1.1 \%(\mathrm{n}=3)$ had asthma. Regarding maternal infections during pregnancy $80.1 \%(n=214)$ did not report of any infections, while the status were unknown for $19.9 \%(n=53)$ of the mothers. Types of congenital anomalies observed with maternal hypertension included congenital absence, atresia and stenosis of anus with fistula; undescended testicles; congenital umbilical hernia; gastroschisis; and conjoined twins. Congenital anomalies observed with maternal diabetes included spina bifida; gastroschisis; polydactyly; congenital umbilical hernia; Down's syndrome; and other congenital heart disease. Those observed with epilepsy included congenital hydrocephalus, down's syndrome, and ventricular septal defect. And those observed with asthma included Turner's syndrome and ambiguous genitalia

\section{Discussions}

This descriptive study was conducted from April 2013 to October 2013 to explore the variations and patterns of distribution of congenital anomalies among children attending the Departments of Pediatric Medicine and Surgery in Dhaka Medical College Hospital. In-depth data were collected from mothers (respondents) and hospital files of 267 children with congenital anomalies.

In the distribution of congenital anomalies according to the body system and site, digestive system occupied the maximum number of anomalies accounting for $27 \%$ of all cases. This was followed by nervous and genitourinary systems each with a percentage of 15.7. Musculoskeletal system occupied the next slot with $15 \%$ which was followed by cardiovascular system, chromosomal abnormality, cleft lip / cleft palate, other chromosomal abnormality and lastly respiratory system. The findings were comparable to various studies carried out in Bangladesh and nearby regions. In a study ${ }^{16}$ in India, the spectrum of surgical congenital anomalies in newborns were investigated, and the results were very similar to the results obtained in the present 
research with the commonest areas affected being the gastro-intestinal tract and the genito-urinary tract $(20.4 \%$ each) followed by the central nervous system. In a similar study ${ }^{12}$, in BSMMU, Bangladesh, musculoskeletal system was found to be most commonly involved, while other anomalies were similar to the current study. At the same time, similar studies in identical settings also showed varied results. Study ${ }^{15}$ of congenital anomalies at birth, in central India, revealed cardiovascular malformations to be most common in live births, followed by musculoskeletal and genitourinary anomalies. According to researchers conducted in Europe by EUROCAT ${ }^{17}$, congenital heart defects (CHD) were the most common non-chromosomal subgroup, at 6.5 per 1,000 births, followed by limb defects (3.8 per 1,000), anomalies of urinary system (3.1 per 1,000) and nervous system defects $\left(2.3\right.$ per 1,000). Congenital Malformations report of $2008{ }^{28}$ of New York Health Department showed cardiovascular system to be the most common followed by genitourinary, muscular, other systems, digestive and others.

Congenital hydrocephalus was found to be most common specific type of anomaly encountered accounting to $8.6 \%$. This was followed by hypospadias $7.9 \%$; Hirschsprung's disease, $7.5 \%$; cleft lip/palate, $6.7 \%$; and gastroschisis. This was very similar to some of the previous studies ${ }^{11}$ in most of which congenital hydrocephalus occupied the most common spot and cleft lip/palate had significant numbers. However, the prevalence of Hirschsprung's disease and gastroschisis were unusually high in Dhaka Medical College Hospital.

Of digestive system anomalies, Hirschsprung's disease accounted for most of the cases $(n=20)$, followed by other anorectal malformations $(n=12)$ and congenital absence, atresia and stenosis of anus with fistula $(n=8)$. Others included congenital hypertrophic pyloric stenosis $(n=7)$; congenital absence, atresia and stenosis of small intestine $(n=6)$; neonatal intestinal obstruction $(n=5)$; congenital absence, atresia and stenosis of anus without fistula / Imperforate anus $(n=5)$; congenital tracheo-esophageal fistula $(n=3)$; meconium ileus $(n=2)$; exomphalosomphalocele $(n=2)$; and congenital absence, atresia and stenosis of rectum without fistula / imperforate rectum $(n=2)$. According to the Congenital Malformations report of $2008{ }^{28}$ of New York Health Department, pyloric stenosis was the most common followed by other anomalies of the intestine; atresia and stenosis of the small intestine; atresia and stenosis of the large intestine; Hirschsprung's disease; gallbladder and liver anomalies; trachea-esophageal fistula; and others. Comparing the two results, there are some similarities in the distribution.

Among the nervous system disorders, congenital hydrocephalus accounted for most of the cases $(n=23)$, followed by meningocele $(n=6)$ and meningomyelocele $(n=5)$. Also found were encephalocele $(n=4)$ and Spina Bifida $(n=4)$. Compared to Congenital Malformations report of $2008{ }^{28}$ of New York Health Department, hydrocephalus was also the most common in New York, followed by others; microcephalus; reduction deformity of brain; spina bifida; anencephaly; and encephalocele.

Hypospadias numbered most $(n=21)$ among the anomalies of the genitourinary system is this research, followed by undescended testicle $(n=6)$ and congenital hydrocele $(n=4)$. Others included cloacal anomaly $(n=3)$; epispadias $(\mathrm{n}=2)$; indeterminate sex, unspecified / ambiguous genitalia $(=2)$; congenital posterior urethral valves $(\mathrm{n}=2)$; and congenital hydronephrosis $(\mathrm{n}=2)$. Hypospadias and epispadias were almost common according to Congenital Malformations report of $2008{ }^{28}$ of New York Health Department, followed by anomalies of renal pelvis, ureter, other kidney disorders.

Among the musculoskeletal anomalies, gastroschisis $(n=16)$ accounted for most, followed by polydactyly $(n=12)$. Other musculoskeletal anomalies found included congenital umbilical hernia $(n=5)$; eventration of diaphragm $(n=4)$; and Club Foot $(n=3)$.

Of the cardiovascular anomalies, ventricular septal defect $(n=8)$ was most common, followed by atrial septal defect $(n=7)$; tetralogy of Fallot $(n=4)$; transposition of the great arteries $(n=3)$; and other congenital heart disease $(n=4)$. Ventricular septal defect and atrial septal defect also occupied the first two most anomaly respectively according to the Congenital Malformations report of $2008^{28}$ of New York Health Department, While tetralogy of Fallot and transposition of great arteries occupied seventh and eighth most common cardiovascular disorders respectively.

Down's syndrome was found to be the most common chromosomal anomaly in the present study and in Congenital Malformations report of $2008{ }^{28}$ of New York Health Department as well. Cleft lip was significant in both studies.

Considering the outcomes of attending congenital anomaly patients, $71.9 \%$ of them were treated and discharged with correction of anomaly while $6.7 \%$ were discharged without correction of anomalies which mostly included patients with chromosomal anomalies; $18.4 \%$ referred to higher centers with only $3 \%(n=8)$ of the patients dying during hospital stay. Among the patients referred most were referred to National Institute of Cardiovascular Diseases, Bangladesh (NICDB). and Dhaka Sishu (Children's) Hospital. These data reflect the high capacity of Dhaka Medical College Hospital in tackling the mass population with congenital anomalies.

Early neonates (1-7 days) were the most frequent age group for seeking medical help for congenital anomalies and accounted for $33.3 \%$ of all cases while school ages (5-14 years) were the least at 7.49\%. The 
remaining age groups were fairly evenly distributed with late neonate (8-27 days) at $15.5 \%$; Post neonate ( $28^{\text {th }}$ day to 1 year) at $24.7 \%$ and preschool age (1-4 years) at $19.1 \%$.

Males accounted for majority of the cases with $52.8 \%$ while $46.4 \%$ were females and $0.7 \%$ had ambiguous genitalia. This is similar to the findings of a study carried out in BSMMU in which 68\% were males while $32 \%$ were females. ${ }^{11}$

Majority of the patients came from Dhaka division, 33.3\%, followed by Khulna, 14.2\%; Barisal, 13.1\%; Rangpur, 12.7\%; Chittagong, 12.4\%; Rajshahi, 8.6\%; and Sylhet, 5.6\%. Patients' resident districts showed a fairly even distribution with patients coming from a wide range of districts of the country. However majority of patients came from Dhaka and nearby districts.

Most of the respondents, 91\%, were Muslims; followed by Hindus, 6.4\%; Christians, $1.5 \%$ and Buddhists $0.4 \%$. None were found to be atheists or of mixed or other religious groups. This is fairly the normal trend of religion in Bangladesh according to the International Religious Freedom Report 2005 stated in Wikipedia according to which Muslims contribute $89.5 \%$ of the population followed by Hindus who contribute 9.6\% and Buddhist, Christians, those who practice other religion and those who do not are the remainders of $0.09 \% .^{29}$

Majority of the mothers were in age group of 21-25 years accounting to $44.9 \%$, followed by the 26-30 year group, $22.1 \%$; $16-20$ years, $16.8 \%$; 31-35 years, $12.4 \%$; and lastly 36 years and above $3.7 \%$. This was similar to the study made in BSMMU. ${ }^{11}$ At the same time, 55.4\% of the fathers were in the age group 25-34 years; $29.6 \%$ were $35-44$ years, $11.2 \%$ were $45-54$ years, $3 \%$ were $15-24$ years and $0.7 \%$ was $55-64$ years.

Identical to the BSMMU study ${ }^{11}, 94 \%$ of the patients did not report of any family history of birth defects. $6 \%$ reported of birth defects in some members of the family. The types of congenital anomalies that were present in those patients with a positive family history were as follows: hypospadias $(n=4)$; congenital hypertrophic pyloric stenosis $(n=2)$ meningocele $(n=2)$; cleft lip/cleft palate $(n=2)$; undescended testicles $(n=2)$; coacal anomaly $(\mathrm{n}=1)$; Down's syndrome $(\mathrm{n}=1)$; Turner's syndrome $(\mathrm{n}=1)$ and other congenital heart disease $(\mathrm{n}=1)$.

96.6\% of the parents had non-consanguineous marriages. Consanguinity was observed among 3.4\% which was found to be less than studies carried out in Kohat, Pakistan ${ }^{31}$. All the consanguinity reported in the present study were between cousins. Patients with congenital anomalies with consanguineous parents showed the following pattern of anomalies: hypospadias $(n=2)$, undescended testicles $(n=2)$, Down's syndrome $(n=1)$, epispadias $(n=1)$, indeterminate sex / ambiguous genitalia $(n=1)$, tetralogy of fallot $(n=1)$ and ventricular septal defect $(\mathrm{n}=1)$.

$40.4 \%$ of the mothers had primary or some school level education (up to or below 6th grade). $30.3 \%$ had education up to secondary school (up to 10th grade); 19.5were illiterate (no formal education); $3.7 \%$ completed higher secondary school (up to college/12th grade); $3 \%$ had undergraduate level education; $1.9 \%$ had some undergraduate education or vocational degrees; and $1.1 \%$ had had post graduate level education. $32.21 \%$ of the fathers had primary or some school level education (up to or below 6th grade). $31.5 \%$ had education up to secondary school (up to 10th grade); $16.1 \%$ were illiterate (no formal education); $12.7 \%$ completed higher secondary school (up to college/12th grade); $3.7 \%$ had undergraduate level education. 2.6\% had some undergraduate education or vocational degrees; and $1.1 \%$ had post graduate level education. This was similar to the Bangladesh Literacy Survey of 2010. ${ }^{31}$ According to the survey, literacy statuses were as follows: class I-V, male: $29.80 \%$, female: $28.30 \%$;class VI-VIII, male: $12.9 \%$, female: $13.63 \%$; class IX-X, male: $7.97 \%$, female: $13.63 \%$; SSC/equivalent, male: $5.86 \%$, female: $4.54 \%$; HSC/equivalent, male: $3.81 \%$, female: 2.84 ; degree/equivalent, male: $2.17 \%$, female: $0.92 \%$; master's/equivalent, male: $1.24 \%$, female: $0.45 \%$; engineering/medical, male: 0.17 , female: 0.05 ; technical/vocational, male: $0.12 \%$, female: $0.04 \%$; and others, male: $0.02 \%$, female: $0.01 \%{ }^{31}$

Majority of mothers, $72.3 \%$, were house wives; $12.7 \%$ were farmers; $9.7 \%$ had clerical or technical jobs; $3 \%$ were hard laborers; $1.9 \%$ were house maids; and $0.4 \%$ held professional or administrative jobs. While, $46.8 \%$ of the fathers held clerical or technical jobs; $25.5 \%$ were farmers; $13.1 \%$ were hard laborers; $12.4 \%$ were involved in business; $1.9 \%$ had professional or administrative jobs; and 0.4 had other occupations.

Vast majority, 58.4\%, of the families having children with congenital anomalies made their living earning 5,000-9,999 Takas (62-125 USD as per average September 2013 conversion rate of $1 \$=80$ Takas); $30.3 \%$ of families earned 10,000-24,999 Takas (125-312 USD); 6\%earned 2,500-4,999 Takas (31-62 USD); $3.8 \%$ earned 25,000-49,999 Takas (312-625 USD); 0.8\% earned less than 2500 Takas ( $<31$ USD); $0.8 \%$ earned 50,000-74,999 Takas (625-938 USD); and 0.4\% earned above 75,000 Takas (>938 USD). Most of the respondents, $41.2 \%(\mathrm{n}=110)$ reported living in rural mud (kacha) type of housing; $38.6 \%$ lived in rural brick (paka) type of housing; $15.4 \%$ lived in urban planned or cramped housing; $4.5 \%$ lived in urban planned housing or residential areas; while $0.4 \%$ reported living in slums. This study revealed that the vast majority of the patients were from socio-economic groups. Similar situations were found in studies in nearby regions including Pakistan ${ }^{31}$.Studies ${ }^{1}$ have shown that majority $(94 \%)^{1}$ of all the congenital malformations occur in middle and 
low income countries. Therefore, the wide occurrence of congenital anomaly in Bangladesh is understandable and factors that persist in lower socioeconomic conditions are likely to play a role in causing congenital anomalies.

Similar to the findings of parity of mothers in a study in Kohat, Pakistan ${ }^{31}, 30 \%$ of mothers had parity of $2,29.6 \%$ had $3 ; 20.2 \%$ had $4 ; 16.9 \%$ had 1 , while $3.4 \%$ had parity of 5 and more. $91.4 \%$ gave no history of previous abortion and $95.5 \%$ gave no history of previous still births.

Similar to the BSMMU research findings ${ }^{11}$ in which $92 \%$ made irregular antenatal care visits and $8 \%$ made regular visits, $42 \%(n=112)$ of the mothers of the present study had no antenatal care visits; $43 \%(n=115)$ had irregular visits; while only $15 \%(\mathrm{n}=40)$ had regular antenatal checkups/screening.

$69.3 \%$ did not take iron, folic acid and vitamin B12 during pregnancy. 30.7\% took iron, folic acid and vitamin B12 supplementation during pregnancy. This was identical to a study in Kohat, Pakistan ${ }^{31}$ in which $66.7 \%$ did not take folic acid supplementation while $33.3 \%$ took supplementation.

Majority of the mothers, $90.6 \%$ did not report of any smoking habits during pregnancy. $9.4 \%$ were passive smokers with fathers being smokers in all the cases of passive smoking. None were found to be active smokers. This also matched with the study in Kohat, Pakistan ${ }^{31}$.

$75.3 \%$ did not report of taking any drugs or medications during pregnancy. $14.6 \%$ did not know if any medications were taken during pregnancy; $3.0 \%$ reported of taking antihypertensive drugs; $2.6 \%$ reported of taking antibiotics but could not specify the name of antibiotics; $2.2 \%$ took some kind of medication but were unable to specify; $1.1 \%$ reported of taking oral hypoglycemic drugs; $0.7 \%$ took antiepileptic drugs; and $0.4 \%$ took some kinds of anti-asthmatic drugs. In the study in Kohat, Pakistan ${ }^{31}$, several medications taken overlapped with this study which includes antiepileptic, insulin and oral hypoglycemic.

$88.4 \%(\mathrm{n}=236)$ of the respondents did not report of having any disease during pregnancy while the disease status of $3 \%(n=8)$ were not known. 3.4\% $(n=9)$ reported of having hypertension during pregnancy; $3 \%$ $(n=8)$ were diabetic; $1.1 \%(n=3)$ had epilepsy; and $1.1 \%(n=3)$ had asthma. Regarding maternal infections during pregnancy $80.1 \%(n=214)$ did not report of any infections, while the status were unknown for $19.9 \%$ $(n=53)$ of the mothers. On the contrary, the study in Kohat, Pakistan ${ }^{31}$, reported scattered incidences of syphilis and toxoplasmosis.

\section{Conclusion}

\section{Conclusion And Recommendations}

A wide variety of congenital anomalies with varying patterns of distribution was recorded among the study subjects. Health care facilities in Dhaka Medical College Hospital were found to be highly adequate in providing affordable mass scale treatment of congenital anomalies with remarkable success rates. However, the socio-economic conditions and educational levels of parents having children with congenital anomalies were found to be under par. In addition, the percentages of patients receiving regular antenatal checkups and vitamin supplementations were found to be alarmingly low, higher percentages of which could have otherwise potentially averted the occurrence of congenital anomalies in at least many of the cases. These aspects including possible lack of awareness about congenital anomalies and its available treatment options could be the main contributing elements in aggravating the burden of birth defects among children in Bangladesh with a resultant higher prevalence compared to more developed nations.

\section{Recommendations}

- The general educational levels and socio-economic conditions should be given more emphasis in the already ongoing efforts by the government, non-governmental and international organizations.

- Awareness about congenital anomalies and its available treatment options and facilities should be developed through various approaches of mass communication and education.

- Provisions of antenatal care which are already in place in various regions of the country should be enhanced and enforced. Community awareness about the necessity of antenatal checkups not only for the benefit of the mothers but also their children should be developed through more vigorous programs.

- Antenatal care should include health education about congenital anomalies and should be more extensive in screening and providing vitamin supplementations for the early detection and prevention of birth defects.

- Neonatal care should be given more emphasis for early detection of birth defects and mothers of children with congenital anomalies should be provided with mental support and thorough guidance regarding the steps to be taken for the betterment of the child.

- Various screening processes and facilities including genetic screening of patients should be made more affordable and accessible to the general population.

- Regional hospitals should be developed for taking some of the burden of treatment of congenital anomalies.

- Further studies in order to investigate the associations of specific risk factors and congenital anomalies should be encouraged. 
[1]. Congenital Anomalies. WHO Fact $\begin{aligned} & \text { References } \\ & \text { sheet N370, October }\end{aligned}$ 2012. Available from http://www.who.int/mediacentre/factsheets/fs370/en/ (accessed on June 14, 2013)

[2]. Stevenson RE, et al. (eds): Human Malformations and Related Anomalies. New York, Oxford University Press, $1993, \mathrm{p} 115$.

[3]. Kumar, Abbas, Fuasto, Mitchel. Robins Basic Pathology. $8^{\text {th }}$ edtion. Elsevier Publications. Pages 252-236.

[4]. Kumar, Abbas, Fuasto. Robins and Cotran Pathologic Basis of Disease. $7^{\text {th }}$ edition. Elsevier Publications.2008. Pages 469-477.

[5]. James LM: Maps of birth defects occurrence in the U.S., birth defects monitoring program (BDMP)/CPHA, 1970-1987. Teratology 48:551, 1993

[6]. The global burden of disease: 2004 update. Geneva, World Health Organization, 2008

[7]. Copeland GE, Kirby RS. Using birth defects registry data to evaluate infant and childhood mortality associated with birth defects: an alternative to traditional mortality assessment using underlying cause of death statistics. Birth Defects Res A Clin Mol Teratol 2007;79(11): 792-7.

[8]. Dolk H, Loane M, Garne E. The prevalence of congenital anomalies in Europe. Adv Exp Med Biol 2010. 686: 349-64.

[9]. Fabricio Gonzalez-Andrade, Ramiro Lopez-Pulles. Congenital Malformations in Ecuadorian Children: Urgent Need to Create National Registry of Birth Defects. Dove Press Journal, The Application of Clinical Genetics. 13th April 2010

[10]. "Online Etymology Dictionary". Available from http://www.etymonline.com/(accessed on $14^{\text {th }}$ June 2013).

[11]. K Fatema, F Begum, N Akter, S M M Zaman. Major Congenital Malformations among The Newborns in BSMMU Hospital. Bangladesh Medical Journal 2011 Vol. 40 No1. January 2011 Issue.

[12]. Khanum S, Noor K, Kawser CA. Studies on congenital abnormalities and related risk factors. Mymensingh Medical Journal. 2004 $\mathrm{Jul} ; 13(2): 177-80$.

[13]. Sunethri Padma, Ramakrishna , Jijiya Bai and Ramana PV. Pattern of Distribution of Congenital Anomalies in Stillborn. International Journal of Pharma and Bio Sciences.Vol 2/ Issue 2/Apr-Jun 2011.

[14]. Arjun Singh, Ravinder K Gupta. Pattern of Congenital Anomalies in Newborn: A Hospital Based Prospective Study. JK Science. Vol. 11 No. 1, January-March 2009.

[15]. Amar Taksande, Krishna Vilhekar, Pushpa Chaturvedi, Manish Jain. Congenital Malformations at birth in Central India: A rural medical college hospital based data. Indian J Hum Genet. 2010 Sep-Dec; 16(3): 159-163. doi: 10.4103/0971-6866.73412

[16]. Ronya R, Gupta D, Ghosh SK, Narang R, Jain KB. Spectrum of congenital surgical malformations in newborns. J. Indian Med assoc. $2002 \mathrm{Sep} ; 100(9): 565-6$

[17]. Dolk H, Loane M, Garne E. The prevalence of congenital anomalies in Europe. EUROCAT Central Registry, Faculty of Life and Health Sciences, University of Ulster, Newtownabbey, UK.

[18]. Fabricio Gonzalez-Andrade, Ramiro Lopez-Pulles. Congenital Malformations in Ecuadorian Children: Urgent Need to Create National Registry of Birth Defects. Dove Press Journal, The Application of Clinical Genetics. 13th April 2010.

[19]. Team of the International Maternal Pediatric Adolescent Aids Clinical Trial Group. Prevalence of Congenital Anomalies in Infants in Infants with in Utero Exposure to Antiretrovirals. Pediatr Infect Dis J.; 31(2): 164-170. doi:10.1097/INF.0b013e318235c7a.2012 February.

[20]. Ridgely Fisk Green, Owen Devine, Krista S. Crider, Richard S. Olney, Natalie Archer, Andrew F. Olshan, et al.Association of Paternal Age and Risk for Major Congenital Anomalies from the National Birth Defects Prevention Study, 1997-2004, Ann Epidemiol. NIH Public Access, 2010 March; 20(3): 241-249.

[21]. Herbert A Obu, Josephat M Chinawa, Nwachinemere D Uleanya,Gilbert N Adimora, and Ikechukwu E Obi Congenital malformations among newborns admitted in the neonatal unit of a tertiary hospital in Enugu, South-East Nigeria - a retrospective study. BMC Res Notes. 2012; 5: 177.Published online 2012 July 10. doi: 10.1186/1756-0500-5-177

[22]. Syuichi Ooki. Maternal age and birth defects after the use of assisted reproductive technology in Japan, 2004-2010. Int J Womens Health. 2013; 5: 65-77.

[23]. Marlene Anderka, Allen A. Mitchell, Carol Louik, Martha M. Werler,Sonia Hernández-Diaz, Sonja A. Rasmussen,and the National Birth Defects Prevention Study. Medications Used to Treat Nausea and Vomiting of Pregnancy and the Risk of Selected Birth Defects. Birth Defects Res A Clin Mol Teratol. 2012 January; 94(1): 22-30.

[24]. Xingguang Zhang, Su Li,Siqintuya Wu, XiaojinHao,ShuyiGuo, Kota Suzuki,Hiroshi Yokomichi, and Zentaro Yamagata. Prevalence of birth defects and risk-factor analysis from a population-based survey in Inner Mongolia, China. BMC Pediatr. 2012; 12: 125

[25]. Min-A Kim, Nan Hee Yee, JeongSoo Choi, Jung Yun Choi, and Kyung Seo. Prevalence of Birth Defects in Korean Live births, 2005-2006.J Korean Med Sci. 2012 October; 27(10): 1233-1240.

[26]. James E. Kucik, Clinton J. Alverson, Suzanne M. Gilboa, and Adolfo Correa. Racial/Ethnic Variations in the Prevalence of Selected Major Birth Defects, Metropolitan Atlanta, 1994-2005. Public Health Rep. 2012 Jan-Feb; 127(1): 52-61.

[27]. Olof Ståhl, Heather A. Boyd, AleksanderGiwercman, Morten Lindholm,Allan Jensen, Susanne KrügerKjær, Harald Anderson, Et Al. Risk of Birth Abnormalities in the Offspring of Men With a History of Cancer: A Cohort Study Using Danish and Swedish National Registries. J Natl Cancer Inst. 2011 March 2; 103(5): 398-406

[28]. New York State Department of Health. Statistical Summary of Children born in 1983-2007: Congenital Malformations Registry. Center of Environmental Health Bureau of Environmental and Occupational Epidemiology. Published 2013.

[29]. 2008 report available at http://www.health.ny.gov/diseases/congenital_malformations/2008/ (accessed on October 27, 2013)

[30]. The World Factbook - Bangladesh [Internet]. Religions. USA: Central Intelligence Agency CIA Publications. 2004. Available from https://www.cia.gov/library/publications/the-world-factbook/geos/bg.html\#People (Accessed on September 29, 2013)

[31]. Report on the Bangladesh Literacy Survey 2010. Industry and Labor Wings, Bangladesh Bureau of Statistics. Ministry of Planning. Published June $2011 . \quad$ Available online http://www.bbs.gov.bd/webtestapplication/userfiles/image/Survey\%20reports/Bangladesh\%20Literacy\%20Surver\%202010f.pdf ( Accessed on September 29, 1013)

[32]. Fouzia Gul, MusarratJabeen, Abdul Sahib Khan. Frequency of Congenital Malformations Associated Risk Factors at Liaqat Memorial Hospital, Kohat. Pakistan. KMUJ 2012; Vol. 4, No. 3: 119-124 


\title{
ANNEX
}

\author{
ABBREVIATIONS \\ AIDS : Acquired Immune Deficiency Syndrome \\ ANC : Antenatal Care \\ aOR : Adjusted Odds Ratio \\ BMI : Body Mass Index \\ BMRC : Bangladesh Medical Research Council \\ BPR : Birth Prevalence Rate \\ CA : Congenital Anomalies \\ CI : Confidence Interval \\ CL/P : Cleft Lip or Palate \\ DM : Diabetes Mellitus \\ EPI : Expanded Programme on Immunization \\ HTN : Hypertension \\ ICD 10 : International Statistical Classification of Diseases and Related Health \\ Problems 10th Revision. \\ NTD : Neural Tube Defect \\ NVP : Nausea and Vomiting of Pregnancy \\ OR : Odds Ratio \\ RR : Relative Ratio \\ SPSS : Statistical Package for Social Science \\ TOPFA : Termination of Pregnancy for Fetal Anomaly \\ WHO : World Health Organization
}

